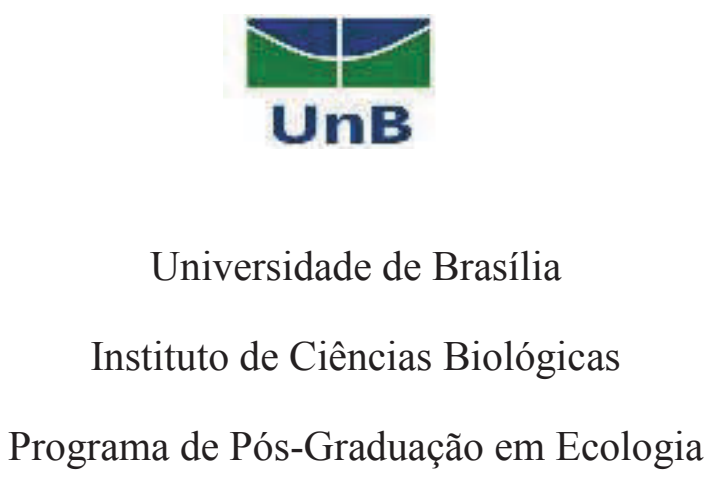

\title{
Padrões Estomáticos e de Condutância Máxima de Vapor D’água em Pares Congenéricos Arbóreos de Cerrado Sensu Stricto e Mata de Galeria
}

\author{
Fernanda Nunes de Araujo Fonseca \\ Orientador: Augusto Cesar Franco
}

Dissertação de Mestrado apresentada ao Programa de Pós-Graduação em Ecologia da Universidade de Brasília, como requisito para obtenção do Título de Mestre.

Brasília/DF 
"São mil coisas impressentidas

Que me escutam:

Sou eu apreensivamente Solicitado pela inflorescência Redescoberto pelo bulir das folhas..."

Manoel de Barros

"The fact that total photosynthesis of plants on land (only one third the surface area) is now about equal to that occurring in the expanse of the oceans is powerful evidence that the move to the land was a boon for plant life - not to mention all the rest of us who eat them. The impact of this innovation was to radically change the climate and ecology of the planet (...). This greening of the land surface was in large part empowered by the evolution of these microscopic, turgor-operated valves, stomata."

Berry, Beerling \& Franks (2010) 


\section{Sumário}

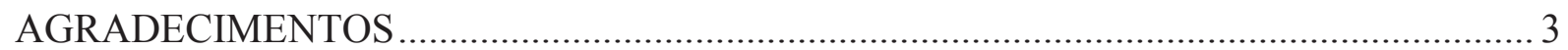

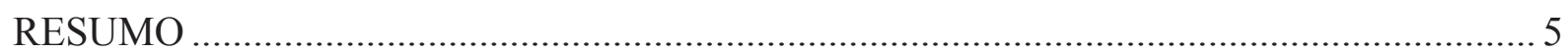

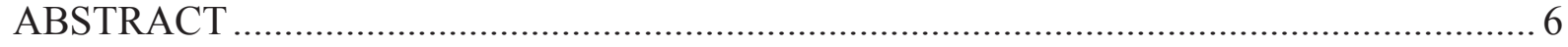

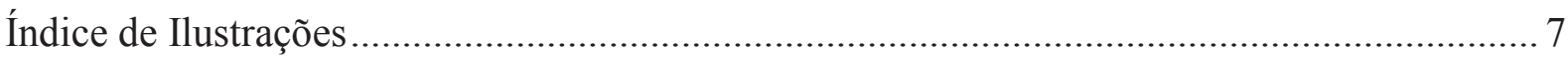

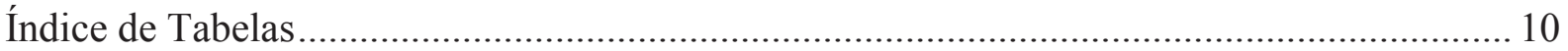

Índice de Abreviaturas, Constantes e Equações ..................................................................... 11

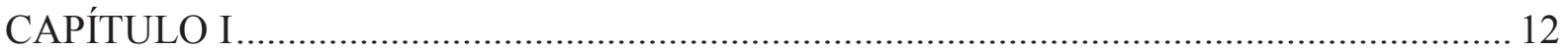

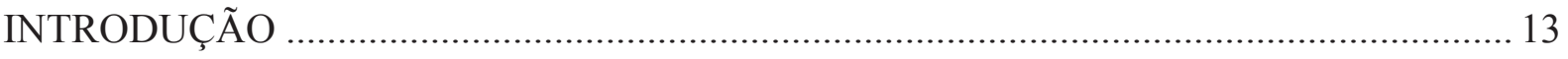

Folhas contam histórias? Por que estudá-las? ........................................................................ 13

Ecofisiologia Vegetal no Cerrado, pares congenéricos arbóreos e objetivos de pesquisa ..... 18

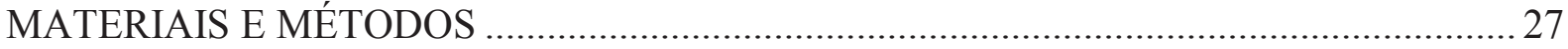

Área de estudo e seleção dos pares congenéricos ................................................................. 27

Coleta das amostras para análises anatômicas, morfológicas e nutricionais ......................... 29

Obtenção das epidermes, análise dos complexos estomáticos e cálculo das condutâncias

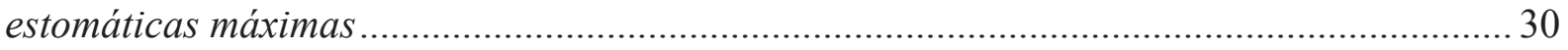

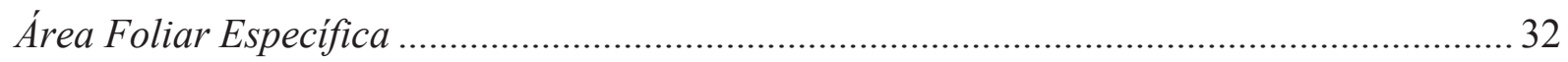

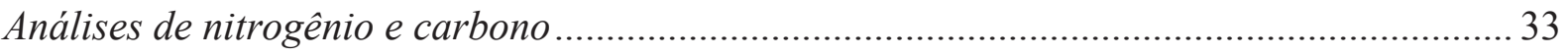

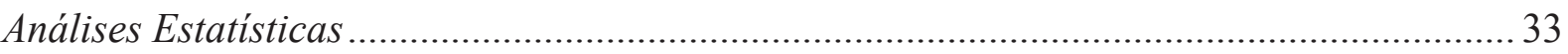

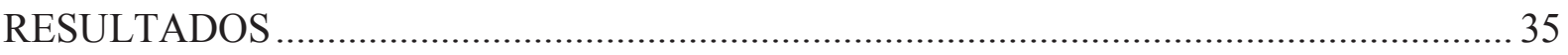

DISCUSS ÃO

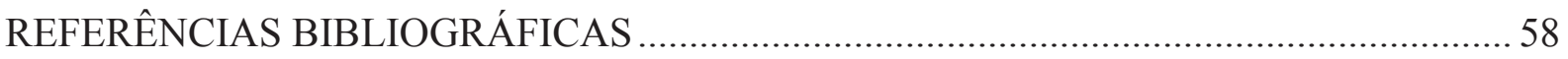

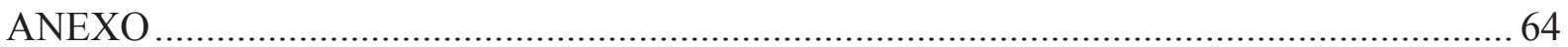




\section{AGRADECIMENTOS}

Agradeço profundamente ao meu avô Sergio, pelo amor e apoio incondicional em minha formação profissional e humana, por toda a vida. Aos meus pais, Sergio Luiz e Kátia, e à minha irmã Renata, pela mesma razão, e por terem acolhido minhas escolhas e suportado meu ethos biólogo, mateiro-viajante vida afora.

Ao Professor Augusto Cesar Franco, cuja competência admiro muito, pelo incentivo acadêmico e paciência com minha falta de tempo para realizar as tarefas nos prazos mais oportunos, e ainda pelas intervenções sempre qualificadas ao longo de todo o processo de maturação de hipóteses de pesquisa e obtenção de dados.

À professora Cristiane Ferreira, pelo fundamental incentivo e apoio emocional em diversas ocasiões, e pela admirável capacidade de transmitir sua empolgação ecofisiológica vegetal em aulas muito aprazíveis.

Ao Mendes, pelo auxílio com as coletas e compartilhamento de sua vasta experiência em identificação botânica, sempre amigo e bem humorado.

À minha chefe, Valéria Carvalho, pela atenção, compreensão, incentivo e carinho com meus processos nas horas em que mais precisei e menos esperei. E à Fundação Nacional do Índio - FUNAI, pela concessão de licença capacitação durante três meses e de redução de carga horária de trabalho, as quais foram fundamentais para a conclusão das disciplinas e dos trabalhos em campo e no laboratório.

À Reserva Ecológica do Roncador - RECOR/IBGE, pelo apoio logístico e concessão da autorização para pesquisa e coleta de material botânico no interior da Unidade de Conservação. 
À professora Sueli Maria Gomes por me deixar sempre à vontade para trabalhar no Laboratório de Anatomia Vegetal e pelas dicas fundamentais de protocolo e registro fotográfico das minhas centenas de seções paradérmicas.

À Jéssica, Isa e Herica, pela paciência em explicar detalhes que não constam nos protocolos.

Ao André pela ajuda com as micrografias e ao William por sanar dúvidas com as metodologias de área foliar e me ajudar na calibração do LAS EZ. E aos demais colegas de laboratório e dos Departamentos de Botânica e Ecologia, pela convivência agradável e frequente partilha de conhecimentos e impressões.

Aos queridos de outras paragens, incluindo Daniel Mattos, Fernanda Braga, Lúcia Sanches, Luísa Coelho e Caroline Lima, que aguentaram minha sofrência ao longo de todo o mestrado e me incentivaram a chegar até o final. Com menção honrosa a Regina Nascimento, a indigenista-poetisa-comunicóloga das mais antropólogas que eu conheço, pelo amor que demonstra pelo Cerrado e interesse em hablar ecologuês comigo, coisa rara fora do IBio.

E aos Programas de Pós-Graduação em Ecologia e em Botânica como um todo, com atenção especial aos professores cujas aulas foram deveras inspiradoras e me transformaram, para além do amor antigo pela Mata Atlântica e Amazônia, numa incontida e eterna admiradora do Cerrado.

Esta dissertação teve apoio do MCTI/Finep/CT-INFRA e do CNPq. 


\section{RESUMO}

Comparamos padrões estomáticos (largura e comprimento das células-guarda, tamanho, área máxima do poro, densidade e índice de área do poro), condutância estomática máxima de vapor d'água calculada ( $\mathrm{g}_{\mathrm{wmax}}$ calculado), concentrações foliares de nitrogênio e carbono e área foliar específica para oito pares congenéricos de espécies lenhosas de cerrado e mata de galeria crescendo numa área transicional entre estas duas fitofisionomias. Encontramos variações significativas para os parâmetros analisados em conjunto, com efeitos significativos de grupo funcional, gênero e da interação grupo x gênero. Espécies de cerrado apresentaram, em média, valores superiores para o índice de área do poro, tamanho estomático e $\mathrm{g}_{\mathrm{wmax}}$, e as densidades foram similares entre os grupos. Em nível de gênero e $\mathrm{g}_{\mathrm{wmax}}$, três pares foram similares, três apresentaram valores superiores para espécies de cerrado e dois para espécies de mata. O índice de área do poro estomático foi similar para cinco pares e maior nas espécies de cerrado dos pares restantes. Nos casos em que diferentes combinações de tamanho e densidade estomática renderam índices de área do poro semelhantes, $\mathrm{o}$ valor de $\mathrm{g}_{\mathrm{wmax}}$ foi mais alto para a espécie com maior densidade estomática, $\mathrm{o}$ que ocorreu tanto para espécies de cerrado como de mata.

Palavras-chave: Savana, Floresta, Estômatos, Condutância Estomática Máxima, Alocação Epidérmica Foliar 


\begin{abstract}
We compared stomata patterns (width and length of the guard cells, size, maximum pore area, density and pore area index), calculated maximum stomatal conductance to water vapour (calculated $\mathrm{g}_{\mathrm{wmax}}$ ), nitrogen and carbon leaf concentrations and specific leaf area for eight congeneric pairs of woody species from cerrado and gallery forest growing in a transitional area between such physiognomies. We found significant variations in the parameters analysed together, with significant effects of functional group, genera and group $\mathrm{x}$ genera interaction. Cerrado species showed, on average, higher values for stomata pore index, stomatal size and $g_{w \max }$, and densities were similar between groups. At genus level and for $\mathrm{g}_{\mathrm{wmax}}$, three pairs were similar, three had higher values for cerrado species and two for forest species. Stomatal Pore Area Index was similar for five pairs and larger in cerrado species of remaining pairs. In cases where different combinations of size and stomatal density yielded similar pore area indexes, the value of $g_{w \max }$ was higher for the species with greater stomatal density, which occurred for both cerrado and forest species.
\end{abstract}

Key-Words: Savanna, Forest, Stomata, Maximum Stomatal Conductance, Allocation of Leaf Epidermal Area 


\section{Índice de Ilustrações}

Figura 1. Esquema contendo características morfológicas, funcionais e estratégias de alocação de recursos esperadas para espécies típicas de cerrado sensu stricto (esquerda) e de mata de galeria (direita). Baseado nos trabalhos de Coley (1985), Franco \& Haridasan (2008), Rossatto et al. (2009a, 2013) e Valladares \& Niinemets (2008). [Nmass] = concentração de nitrogênio por massa foliar.

Figura 2. Precipitação anual na região de estudo para o período de 2005-2014. Gráfíco baseado nas planilhas de dados pluviométricos disponibilizadas on line pela Recor-IBGE (http://www.recor.org.br).

Figura 3. Micrografias das epidermes foliares abaxiais das espécies, organizadas por pares congenéricos e por grupo. Para Byrsonima, Guapira, Hymenaea e Pouteria, as espécies de cerrado apresentaram estômatos maiores em relação as espécies de mata $(P<0.05)$. Densidades estomáticas semelhantes entre espécies de cerrado e mata para Byrsonima e Pouteria, e maiores para espécies de mata em Guapira e Hymenaea $(P<0.05)$. Barra de escala $=50 \mu \mathrm{m}$.

Figura 4. Micrografias das epidermes foliares abaxiais das espécies, organizadas por pares congenéricos e por grupo, para os gêneros Qualea, Tabebuia, Vochysia e Xylopia. Para Qualea, a espécie de cerrado apresentou maior densidade estomática e tamanho estomático similar à espécie de mata $(P<0.05)$. Para Tabebuia e Vochysia, as espécies de cerrado e mata apresentaram tamanhos e densidades estomáticas similares $(P<0.05)$. Para Xylopia, a espécie de cerrado apresentou maior tamanho e maior densidade em relação à congênere de mata $(P<$ 0.05). Barra de escala $=50 \mu \mathrm{m}$.

Figura 5. Amplitude de variação no comprimento da célula-guarda (A), largura do par de células-guarda (B) e tamanho estomático (C) para os conjuntos de espécies de cerrado e de mata. Em todos os gráficos, o outlier superior entre as espécies de cerrado corresponde a Guapira noxia, e em (B) o outlier inferior corresponde a Xylopia aromatica. Diferenças estatisticamente significativas entre os grupos foram encontradas para todos os parâmetros $(P$ $<0.05)$

Figura 6. Amplitude de variação na densidade estomática (A), índice de área do poro estomático (B) e condutância máxima de vapor d'água (C) para espécies de cerrado e de mata. Em (A), o outlier superior das entre as espécies de mata corresponde a Hymenaea courbaril. Os outliers superiores para o índice estomático correspondem a Vochysia thyrsoidea (cerrado) e Vochysia tucanorum (mata). Diferenças estatisticamente significativas entre grupos foram encontradas apenas para o índice de área do poro estomático e a condutância estomática máxima, " $\mathrm{g}_{\mathrm{wmax}}$ " $(P<0.05)$ 40 
Figura 7. Amplitude de variação na área foliar específica (A), concentração de nitrogênio por área foliar (B) e concentração de carbono por área foliar (C) para espécies de cerrado e de mata. Os outliers superiores para a concentração de nitrogênio por área foliar correspondem a Guapira noxia (cerrado) e Guapira graciliflora (mata). Diferenças estatisticamente significativas entre grupos foram encontradas apenas para a área foliar específica $(P<0.05)$.

Figura 8. Relação entre densidade estomática (D) e condutância estomática máxima de vapor d'água, $g_{w \max }$. Cada ponto corresponde a uma espécie. Espécies de cerrado em azul $\left(\mathrm{R}^{2}=\right.$ $0.87, P<0.0001$ e de mata em laranja $\left(\mathrm{R}^{2}=0.81, P=0.002\right)$. A comparação entre as linhas alométricas dos grupos não apontou diferenças significativas entre inclinações (slopes) das retas (likelihood ratio statistic $=3.022, \mathrm{df}=1, P=0.08$ ).

Figura 9. Relação entre o índice de área do poro estomático, SPI, e condutância estomática máxima de vapor d'água, $\mathrm{g}_{\mathrm{wmax}}$. Cada ponto corresponde a uma espécie. Espécies de cerrado em azul $\left(\mathrm{R}^{2}=0.65, P=0.01\right)$ e de mata em laranja $\left(\mathrm{R}^{2}=0.88, P=0.001\right)$. Á direita, espécies tomadas em conjunto $\left(\mathrm{R}^{2}=0.75, P<0.0001\right)$. A comparação entre as linhas alométricas dos grupos não apontou diferenças significativas entre inclinações (slopes) das retas (likelihood ratio statistic $=1.257, \mathrm{df}=1, P=0.26)$.

Figura 10. (A) Relação entre densidade estomática, "D", e a concentração de nitrogênio por área foliar, por grupos funcionais $\left(\mathrm{R}^{2}=0.003, P=0.90\right.$ para espécies de cerrado e $\mathrm{R}^{2}=0.17, P$ $=0.36$ para mata) e (B) para as espécies tomadas em conjunto $\left(\mathrm{R}^{2}=0.04, P=0.51\right)$. A comparação entre as linhas alométricas dos grupos não apontou diferenças significativas entre inclinações (slopes) das retas (likelihood ratio statistic $=0.1923, \mathrm{df}=1, P=0.66$ ). (C) Relação entre o tamanho estomático, "S", e concentração de nitrogênio por área foliar, por grupos funcionais $\left(\mathrm{R}^{2}=0.87, P=0.002\right.$ para espécies de cerrado e $\mathrm{R}^{2}=0.001, P=0.96$ para espécies de mata) e (D) para o conjunto de espécies $\left(\mathrm{R}^{2}=0.10, P=0.26\right)$. A comparação entre as linhas alométricas dos grupos não apontou diferenças significativas entre inclinações (slopes) das retas (likelihood ratio statistic $=0.05245, \mathrm{df}=1, P=0.82$ ). Espécies de cerrado em azul e de mata em laranja. Cada ponto corresponde a uma espécie, sendo que as espécies Guapira noxia e G. gracilifora foram excluídas da análise em razão de apresentarem concentrações médias deste elemento por área foliar muito díspares em relação ao conjunto de dados (outliers)

Figura 11. Relação entre condutância estomática máxima de vapor d'água $\left(g_{\mathrm{wmax}}\right)$ e concentração foliar de nitrogênio em base de área por grupos funcionais $\left(\mathrm{R}^{2}=0.10, P=0.48\right.$ para espécies de cerrado e $\mathrm{R}^{2}=0.12, P=0.45$ para mata) e para as espécies tomadas em conjunto $\left(\mathrm{R}^{2}=0.10, \mathrm{p}=0.27\right)$. Cada ponto corresponde a uma espécie, sendo que as espécies Guapira noxia e G. gracilifora foram excluídas da análise em razão de apresentarem concentrações médias deste elemento por área foliar muito díspares em relação ao conjunto de dados (outliers). A comparação entre as linhas alométricas dos grupos não apontou diferenças 
significativas entre inclinações (slopes) das retas (likelihood ratio statistic $=0.0054, \mathrm{df}=1, \mathrm{p}=$ 0.94). Espécies de cerrado em azul e de mata em laranja.

Figura 12. Relação entre densidade (D) e tamanho (S) dos estômatos, para espécies de cerrado $\left(\mathrm{R}^{2}=0.51, P=0.04\right)$ e mata $\left(\mathrm{R}^{2}=0.07, P=0.53\right)$ à esquerda e para as o conjunto de espécies à direita $\left(\mathrm{R}^{2}=0.09, P=0.25\right)$. Cada ponto corresponde a uma espécie. A comparação entre as linhas alométricas dos grupos não apontou diferenças significativas entre inclinações (slopes) das retas (likelihood ratio statistic $=0.4732, \mathrm{df}=1, P=0.49$ ). Espécies de cerrado em azul e de mata em laranja.

Figura 13. Relação entre área foliar específica (SLA) e concentração nitrogênio por área foliar para (A) espécies de cerrado $\left(\mathrm{R}^{2}=0.63, P=0.03\right)$ e de mata $\left(\mathrm{R}^{2}=0.50, P=0.07\right)$ e (B) para o conjunto de espécies $\left(\mathrm{R}^{2}=0.43, P=0.01\right)$. Espécies de cerrado em azul e de mata em laranja. Cada ponto corresponde a uma espécie, sendo que as espécies Guapira noxia e G. gracilifora foram excluídas da análise em razão de apresentarem concentrações médias deste elemento por área foliar muito díspares em relação ao conjunto de dados (outliers). A comparação entre as linhas alométricas dos grupos não apontou diferenças significativas entre inclinações (slopes) das retas (likelihood ratio statistic $=0.07103, \mathrm{df}=1, P=0.79$ ) $\ldots . . .50$ 


\section{Índice de Tabelas}

Tabela 1. Lista de espécies estudadas e suas famílias botânicas, fitofisionomias típicas de ocorrência, data e local das coletas. 28

Tabela 2. Amplitudes e médias por grupo para os dados de comprimento da célula-guarda (L), largura do par de células-guarda (W), tamanho estomático (S), densidade estomática (D), condutância estomática máxima de vapor d'água $\left(\mathrm{g}_{\mathrm{wmax}}\right)$, índice de área do poro estomático (SPI), área foliar específica (SLA), concentração de carbono (C) e nitrogênio $(\mathrm{N})$ por área foliar. Diferenças significativas entre grupos indicadas por asteriscos $(* * *$ para $P<0.0001$, ** para $P<0.001$, * para $P<0.05$ ). 36

Tabela 3. Análise Multivariada de Variância (MANOVA) para efeitos de grupo funcional (mata/cerrado) e gênero, incluindo a interação grupo x gênero. Diferenças significativas apontadas por asteriscos (*** quando $P<0.0001$, ** quando $P<0.001$, * quando $P<0.05$ ).

Tabela 4. Análises univariadas de variância (ANOVAs fatoriais) para cada variável estudada, considerando os fatores grupo funcional, gênero e a interação grupo x gênero. Diferenças significativas apontadas por asteriscos $(* * *$ para $P<0.0001$, ** para $P<0.001$, * para $P<$ $0.05)$

Tabela 5. Resumo dos resultados apontados pelos testes t pareados para tamanho estomático (S), densidade estomática (D), índice de área do poro estomático (SPI) e condutância estomática máxima teórica $\left(\mathrm{g}_{\mathrm{wmax}}\right)$. Resultados indicados por "Maior" e "Menor" indicam diferença estatisticamente significativa, para cada parâmetro $(P<0.05)$, entre as espécies de cerrado comparadas às de mata de cada par congenérico. Os resultados condizentes com as hipóteses do trabalho foram destacados em verde, e os diferentes do esperado em vermelho.45

Tabela 6. Comparação entre condutâncias operacionais $\left(g_{s}\right)$ e teóricas $\left(g_{w m a x}\right)$ para os gêneros em comum entre este trabalho e Rossatto et al. (2009b), sendo " $g_{\text {wmax }}$ lit" a condutância teórica calculada com base neste último. Diferenças estatisticamente significativas entre espécies de mata e de cerrado, em cada um dos trabalhos, encontram-se destacadas em negrito 


\section{Índice de Abreviaturas, Constantes e Equações}

$\mathrm{L}=$ "Length" = Comprimento Médio da Célula-Guarda $(\mu \mathrm{m})$

$\mathrm{W}=$ "Width" = Largura Média do Par de Células-Guarda $(\mu \mathrm{m})$

$\mathrm{S}=$ "Size" = Tamanho Médio do Estômato, sendo $\mathrm{S}=\mathrm{L} * \mathrm{~W}\left(\mu \mathrm{m}^{2}\right)$

$\mathrm{a}_{\max }=$ Área Máxima do Poro Estomático, sendo $\mathrm{a}_{\max }=\mathrm{S} * \alpha\left(\mu \mathrm{m}^{2}\right)$

$\mathrm{D}=$ "Stomata Density" = Densidade Estomática (número de estômatos por $\mathrm{mm}^{2}$ )

$\mathrm{d}=$ Difusividade da Água no Ar, sendo $\mathrm{d}=2,57 \times 10^{-5} \mathrm{~m}^{2} \mathrm{~s}^{-1}$

$\mathrm{v}=$ Volume Molar do Ar, sendo $\mathrm{v}=0,022413968 \mathrm{~m}^{3} \mathrm{~mol}^{-1}$

$1=$ Profundidade do Poro Estomático, sendo $1=\mathrm{W} / 2(\mu \mathrm{m})$

$\mathrm{g}_{\mathrm{wmax}}=$ condutância estomática máxima de vapor d'água, sendo $\mathrm{g}_{\mathrm{wmax}}=\frac{(\boldsymbol{d} \times \boldsymbol{D} \times \boldsymbol{a m a x})}{\boldsymbol{v} \times\left(\boldsymbol{l}+\frac{\pi}{2} \times \sqrt{\frac{\boldsymbol{a m a x}}{\pi}}\right)}$

SPI = "Stomatal Pore Area Index" = Índice de Área do Poro Estomático, sendo SPI = L * D

$[\mathrm{N}]=$ concentração de nitrogênio por área foliar $\left(\mu \mathrm{g} \cdot \mathrm{mm}^{-2}\right)$

$[\mathrm{C}]=$ concentração de carbono por área foliar $\left(\mu \mathrm{g} \cdot \mathrm{mm}^{-2}\right)$

$\mathrm{SLA}=$ "Specific Leaf Area" $=$ Área Foliar Específica $=\frac{\text { área foliar }}{\text { massa } \text { seca foliar }}\left(\mathrm{cm}^{2} / \mathrm{g}\right)$ 
CAPíTULO I 


\section{INTRODUÇÃO}

\section{Folhas contam histórias? Por que estudá-las?}

Folhas verdes são fundamentais para o funcionamento dos ecossistemas terrestres, sendo seus pigmentos o sinal predominante visto do espaço (Wright et al. 2004). Apesar das diferenças marcantes entre as espécies vegetais em termos de história evolutiva, as mesmas apresentam, independentemente do bioma analisado, padrões similares de tradeoffs entre estrutura e função foliar e taxas de crescimento, o que sugere convergência evolutiva e certa generalidade no funcionamento das plantas (Reich et al. 1997, Wright et al. 2004).

Características foliares são comumente associadas com a história de vida, distribuição e requerimentos das espécies por recursos (Hoffmann et al. 2005), e o estudo das relações funcionais das plantas tem implicações significativas para a modelagem das trocas de gás carbônico vegetação-atmosfera em escala global (Reich et al. 1997). A obtenção de nitrogênio, a assimilação de carbono e a decomposibilidade das folhas dirigem ciclos biogeoquímicos, sendo que animais, fungos e outros heterótrofos são abastecidos pelo fotossintato e têm seus habitats estruturados pelos caules nos quais as folhas são implantadas (Wright et al. 2004).

Existe uma relação de interdependência funcional entre fotossíntese, conteúdo de nitrogênio, estrutura e longevidade foliar, sendo que espécies vegetais que apresentam elevada área foliar específica (relação área /massa foliar), elevado conteúdo de nitrogênio em base de massa foliar, alta capacidade fotossintética e curto tempo de vida foliar apresentam taxas elevadas de crescimento relativo (Reich et al. 1997). Tais tradeoffs são uma provável 
consequência das estratégias de crescimento rápido vs. crescimento lento das plantas (Coley 1985).

O nitrogênio é um macronutriente essencial para o crescimento e desenvolvimento das plantas, sendo obtido pelas raízes sob a forma de $\mathrm{NO}^{3-}$ ou $\mathrm{NH}_{4}^{+}$e conduzido para as folhas, onde passa a integrar proteínas do maquinário fotossintético, especialmente a enzima Rubisco (ribulose bifosfato carboxilase oxigenase) (Taiz \& Zeiger 2013). Uma proporção substancial de variação na capacidade fotossintética é explicada pelo conteúdo foliar de nitrogênio, sendo que o gradiente de $\mathrm{CO}_{2}$ no interior da folha também é afetado pela estrutura foliar (Reich 1997).

Cumpre observar que uma elevada área foliar específica, alta capacidade fotossintética e o consequente turnover rápido de partes vegetais permitem uma resposta mais flexível das plantas à heterogeneidade espacial de luz e de recursos do solo (Wright et al. 2004). Por outro lado, tal combinação de atributos morfofuncionais pressupõe concentrações de nitrogênio em base de massa elevadas e pode aumentar a vulnerabilidade à herbivoria e as perdas de carbono via respiração, o que pode ser prejudicial para a planta num cenário de baixo ganho de energia devido à disponibilidade de recursos reduzida, bem como em condições limitantes de luminosidade (Wright et al. 2004).

Embora a luz seja um recurso imprescindível para a fotossíntese, tanto irradiações muito baixas como muito altas podem limitar o desempenho das plantas, que tendem a diferir umas das outras em um grande número de características fisiológicas e estruturais conforme suas capacidades de tolerância ao sombreamento, tendo sido sugerido que tal tolerância depende da eficiência no ganho de carbono sob baixa luminosidade e também da tolerância a estresses que interagem com a disponibilidade luminosa (Valladares \& Niinemets 2008). 
Outro insumo-chave ao processo de fixação de carbono, além de luz e nitrogênio, é a água, que constitui o meio no qual nutrientes e fotoassimilados são transportados no interior da planta. Quando os estômatos estão abertos, permitindo a difusão de $\mathrm{CO}_{2}$ para o interior da folha, inevitavelmente a planta perde água por transpiração, um importante processo de dissipação de energia e que contribui decisivamente para a regulação da temperatura foliar. Além disso, as moléculas de água são quebradas durante a fotossíntese de tal modo que o hidrogênio é incorporado a açúcares intermediários (Wright et al. 2003).

Estômatos consistem em pares de células epidérmicas especializadas denominadas células-guarda, com frequência reniformes e com um ostíolo entre elas, cujo tamanho é regulado por alterações em seu formato (Cutler et al. 2009). As células-guarda funcionam como válvulas hidráulicas multissensoriais e são sensíveis à intensidade e qualidade luminosa, temperatura, status hídrico foliar e concentração interna de $\mathrm{CO}_{2}$, de tal modo que as condições ambientais internas e externas são percebidas de maneira integrada pelas folhas e isso desencadeia respostas estomáticas concretas, ou seja, variações na abertura do ostíolo ou fenda estomática (Taiz \& Zeiger, 2013 p. 99). À medida que a pressão hidrostática foliar se altera, o par de células-guarda deforma de maneira regulada, com o auxílio de espessamento de parede especializado desuniforme (Cutler et al. 2009).

Nas folhas, os estômatos podem ocorrer em ambas as faces epidérmicas (folhas anfistomáticas) ou somente numa delas, na face abaxial (folhas hipostomáticas, padrão comum entre as plantas dicotiledôneas) ou adaxial (folhas epistomáticas, típicas de plantas aquáticas) (Vannucci \& Rezende 2003). Existem quatro tipos mais comuns de estômatos: (i) anomocíticos (células-guarda circundadas por células muito semelhantes às demais células epidérmicas, caso em que não há células subsidiárias); (ii) anisocíticos (células-guarda circundadas por três células subsidiárias de diferentes tamanhos); (iii) paracíticos (duas 
células subsidiárias cujos eixos mais longos são paralelos aos das células-guarda); (iv) diacíticos (duas células subsidiárias cujos eixos mais longos dispõem-se em ângulo reto com os eixos maiores das células-guarda) (Metcalfe \& Chalk 1979).

A taxa de decaimento da concentração interna de $\mathrm{CO}_{2}$ nas folhas em relação à concentração ambiente pode ser entendida como um balanço entre condutância estomática e capacidade fotossintética (Lambers et al. 1998). Quanto maior a condutância, menor o decaimento interno de $\mathrm{CO}_{2}$ para uma dada capacidade fotossintética, e quanto maior a capacidade fotossintética, mais rápido o decaimento da concentração interna de $\mathrm{CO}_{2}$ em relação à externa, para uma dada condutância (Wright et al. 2003). Portanto, para uma determinada condutância estomática por área epidérmica foliar, devemos esperar que maiores concentrações internas de nitrogênio se traduzam num decaimento mais rápido da concentração foliar de $\mathrm{CO}_{2}$, e consequentemente numa maior capacidade fotossintética.

Taiz \& Zeiger (2013) ensinam que dois tipos de resistência interferem na transpiração foliar, a resistência da camada limitrofe de ar e a resistência estomática, sendo que vários aspectos anatômicos e morfológicos foliares podem influenciar a espessura da camada limítrofe de ar ao seu redor e, deste modo, a resistência limítrofe à difusão do vapor d'água na rota transpiratória (por exemplo, quanto mais vento e menor a área foliar, menor a resistência limítrofe). Segundo os autores, sob condições de baixa resistência limítrofe, a resistência estomática controla em grande parte a perda de água e a entrada de $\mathrm{CO}_{2}$, evidenciando o papel crucial do controle das aberturas estomáticas pelas células-guarda sobre os ajustes de curto prazo na transpiração foliar. Para a rota de difusão do $\mathrm{CO}_{2}$ atmosférico até o interior das folhas existe, além das resistências limítrofe e estomática, a resistência da fase líquida, na qual, a partir dos espaços intercelulares do mesofilo, o $\mathrm{CO}_{2}$ se dissolve na água das paredes 
celulares umedecidas e atravessa o citosol das células até alcançar os sítios de carboxilação, localizados nos cloroplastos (Taiz \& Zeiger 2013).

Embora a área alocada para poros estomáticos ocupe cerca de 5\% da superfície foliar total, a taxa de perda de vapor d'água pode alcançar valores tão altos como $70 \%$ de uma estrutura similar sem a cutícula (Hetherington \& Woodward 2003). Desta maneira, os estômatos exercem um papel central na regulação dos balanços hídrico e de carbono nas plantas, sendo o controle da abertura estomática essencial para a capacidade de tolerância ao déficit hídrico, a qual é fundamental, por sua vez, à sobrevivência de espécies em ambientes expostos a secas sazonais. Depreende-se que o estudo de aspectos anatômicos foliares em nível celular e de tecidos tem grande utilidade para inferir adaptações a ambientes específicos (Fahn 1986 apud Somavilla et al. 2013), podendo render bons indicadores de desempenho das plantas (Poorter \& Bongers 2006) devido às suas relações comuns e fortes com parâmetros funcionais como fotossíntese, conteúdo nutricional foliar e crescimento radial (Rossatto et al. 2009a).

Em termos globais, a precipitação anual sobre a superfície terrestre é de aproximadamente $110.000 \mathrm{~km}^{3}$ ou $110 \times 10^{15} \mathrm{~kg}$, e a evaporação e transpiração totais são de $70 \times 10^{15} \mathrm{~kg}$ (Jackson et al. 2001). A contribuição individual da transpiração estomática com o ciclo hídrico global pode ser estimada usando um modelo dinâmico de vegetação (Sheffield Dynamic Global Vegetation Model, SDGVM), por meio do qual se verifica que as maiores taxas de transpiração ocorrem nas florestas tropicais, com $32 \times 10^{15} \mathrm{~kg}$.ano-1 de vapor d'água passando através de estômatos, o que representa o dobro do conteúdo atmosférico de vapor d'água (Cramer et al. 2001). Portanto, os estômatos são os principais controles sobre os ciclos de água e carbono no mundo (Hetherington \& Woodward 2003). 
Ressaltamos, para além da importância dos órgãos foliares na produção de conhecimento sobre a história evolutiva e no desenvolvimento de sistemas de classificação das espécies botânicas (filotaxia), a necessidade de condução de estudos anatômicos foliares integrados a investigações ecofisiológicas vegetais, uma vez que os dados resultantes podem ser trabalhados em múltiplas escalas ecológicas e contribuir com a modelagem de trocas gasosas vegetação-atmosfera em nível ecossistêmico.

\section{Ecofisiologia Vegetal no Cerrado, pares congenéricos arbóreos e objetivos de pesquisa}

O Cerrado situa-se sobre o platô central do Brasil. Trata-se de uma região de clima sazonal, alta riqueza e diversidade de espécies da flora e fauna, com solos geralmente ácidos e pobres em nutrientes e distribuída por uma área superior a $2.000 .000 \mathrm{~km}^{2}$ (segundo maior bioma brasileiro depois da Amazônia) ${ }^{1}$, embora estimativas recentes indiquem que menos de $20 \%$ de sua cobertura exista em seu estado "original” (Franco \& Haridasan 2008).

Ocorre em altitudes que variam de 300 a 1.600 metros e apresenta solos predominantemente latossólicos, tanto em áreas sedimentares quanto em terrenos cristalinos, ou ainda, em grandes extensões, solos concrecionários (Sano et al. 2008; Lopes 1984 apud Sano et al. 2008). O clima é caracterizado por invernos secos e verões chuvosos (predominantemente Aw ou tropical chuvoso, conforme o sistema de Köppen), com média anual de precipitação de $1.500 \mathrm{~mm}$, variando de $750 \mathrm{~mm}$ a $2.000 \mathrm{~mm}$, sendo as chuvas concentradas entre outubro e março (Adámoli et al. 1987 apud Sano et al. 2008).

A cobertura vegetal é um mosaico complexo de campos, savanas e florestas, apresentando como tipos mais proeminentes o cerrado sensu stricto (cerrado s.s.),

\footnotetext{
${ }^{1}$ Conforme observam Franco \& Haridasan (2008), embora "bioma" seja um conceito global, muitos autores brasileiros consideram o Cerrado como um bioma por si só, contrastando com as savanas na África e Austrália.
} 
fitofisionomia de savana altamente diversa em termos de espécies herbáceas e lenhosas, e as matas de galeria, as quais formam faixas estreitas de vegetação arbórea ao longo de córregos e contêm aproximadamente um terço das espécies lenhosas encontradas em todo o bioma (Sano et al. 2008).

Tais fitofisionomias conformam condições ambientais drasticamente distintas e que impõem diferentes restrições à distribuição das espécies. No cerrado s.s. as plantas estão sujeitas a altas irradiações, baixa disponibilidade de nutrientes, seca sazonal e a distúrbios de fogo associados à seca. Já as matas de galeria apresentam uma camada densa de dossel, o que reduz consideravelmente a entrada de irradiação solar e produz forte heterogeneidade espacial e temporal no que se refere a esse recurso, além de ocorrerem em solos com maior conteúdo de água e nutrientes em relação ao cerrado s.s. (Capuzzo et al. 2012, Franco et al. 2014).

Diversas pesquisas têm sido desenvolvidas no Cerrado com o intuito de estudar diferenças ecofisiológicas e adaptativas entre espécies arbóreas savânicas e florestais que ocorrem naturalmente neste bioma. Tais esforços visam à ampliação do arcabouço científico teórico e conceitual no que se refere ao conjunto de fatores abióticos e bióticos que interferem no recuo ou avanço da fitofisionomia florestal em direção à savana, contribuindo, inclusive, com a composição de cenários fitoecológicos esperados diante das mudanças climáticas globais em curso.

Estudos filogenéticos envolvendo lenhosas do Cerrado apontam que diversas linhagens de espécies de cerrado s.s. evoluíram independentemente a partir de linhagens florestais (matas de galeria) ao longo dos últimos 10 milhões de anos, coincidindo temporalmente com a ascensão à dominância de gramíneas $\mathrm{C}_{4}$ inflamáveis e com a expansão das savanas em todo o mundo (Simon \& Pennington 2012). Como resultado, muitos gêneros 
contêm espécies características das duas fitofisionomias, permitindo o estudo comparativo de pares congenéricos de espécies sujeitas a diferentes pressões seletivas (Rossatto et al. 2013). Alguns autores consideram as espécies savânicas que compõem estes pares como um grupo funcional distinto em relação ao grupo de espécies de mata (Hoffmann et al. 2005), abordagem que buscamos reforçar nesta dissertação.

Já sabemos que os referidos grupos funcionais diferem nos padrões de crescimento inicial e alocação de biomassa, com um maior investimento das espécies savânicas em estruturas subterrâneas e de resistência ao fogo e ocorrendo, por parte das espécies florestais, maior investimento em biomassa aérea, especialmente em área foliar e biomassa do caule (Capuzzo et al. 2012; Franco \& Haridasan 2008; Hoffmann et al. 2005; Hoffmann et al. 2012; Rossatto et al. 2009a).

Árvores de mata de galeria e de cerrado s.s. contrastam fortemente, portanto, em suas respostas às condições de luminosidade (Barros et al. 2012), de disponibilidade de água e nutrientes no solo, sendo que espécies florestais tendem a investir mais em características relacionadas à maximização da tolerância ao sombreamento, enquanto espécies savânicas investem em traços que otimizam a tolerância à irradiação intensa, ao estresse hídrico sazonal, à herbivoria, ao fogo e à baixa disponibilidade de nutrientes (Figura 1).

Embora pouco se saiba sobre restrições a variações nas características foliares impostas por forças seletivas e pela história evolutiva durante o processo de invasão da savana por espécies florestais, supõe-se que a ecologia das espécies congêneres supramencionadas tenha um papel determinante na estruturação e na dinâmica das áreas limitrofes entre seus habitats de origem, isto é, as transições cerrado-mata de galeria (Rossatto et al. 2013). 
Note-se que as pesquisas envolvendo pares congenéricos no Cerrado têm sido concentradas na medição e comparação de atributos funcionais e morfológicos das folhas, dentre as quais citamos: avaliação da concentração de nutrientes foliares e isótopos estáveis de carbono e nitrogênio $\left(\delta^{13} \mathrm{C}\right.$ e $\left.\delta^{15} \mathrm{~N}\right)$ em relação à área foliar específica para 14 pares congenéricos (Hoffmann et al. 2005); análise de diferenças morfológicas (área foliar, espessura foliar, espessura e comprimento peciolar, densidade foliar e área foliar específica) e funcionais (assimilação de $\mathrm{CO}_{2}$, condutância estomática, respiração, eficiência no uso da água e concentração de pigmentos fotossintéticos) para um par congenérico (Capuzzo et al. 2012); estudo de relações entre área foliar específica, taxas fotossintéticas e incrementos mensais na circunferência do caule, comprimento de ramos, padrões sazonais de produção e queda de folhas para 12 pares congenéricos (Rossatto et al. 2009a); comparação de padrões sazonais em características foliares relacionados à estrutura, assimilação de carbono, água e nutrientes para 10 pares congenéricos (Rossatto et al. 2013).

No que concerne trabalhos anatômicos, foi feita uma análise de características estomáticas em relação a valores de condutância estomática e transpiração medidos em campo para 10 pares congenéricos (Rossatto et al. 2009b). Nesta, o autor demonstrou que, em áreas de transição cerrado-mata protegidas contra o fogo, as espécies de mata estudadas conseguem se estabelecer e produzir, em média, folhas com densidades estomáticas semelhantes às espécies de cerrado, alcançando valores estatisticamente similares entre os grupos funcionais tanto para a condutância estomática operacional ${ }^{2}$ como para a assimilação média de $\mathrm{CO}_{2}$ em base de massa ${ }^{3}$, além de padrões de sazonalidade semelhantes para essas variáveis. Por outro lado, as espécies de cerrado apresentaram médias de assimilação de $\mathrm{CO}_{2}$ em base de área

\footnotetext{
${ }^{2}$ Exceto no mês de setembro, em que a condutância estomática foi superior para o grupo de espécies de cerrado.

${ }^{3}$ Superior para as espécies de mata apenas em janeiro, pico da estação chuvosa.
} 
estatisticamente superiores ao grupo de mata durante a maior parte do ano, além de estômatos maiores (comprimentos e larguras das células-guarda e áreas dos poros estomáticos maiores). 


\section{Crescimento lento}

\section{$<$ Área Foliar Especifica}

$<$ [Nmass $]$ foliar

$<$ Capacidade Fotossintética

$>$ Longevidade Foliar

$>$ Investimento em biomassa subterrânea

$>$ Investimento em estruturas de proteção contra o fogo e ressecamento

Metabólitos de defesa anti-herbivoria

minimizacão do estresse por dêficit hídrico

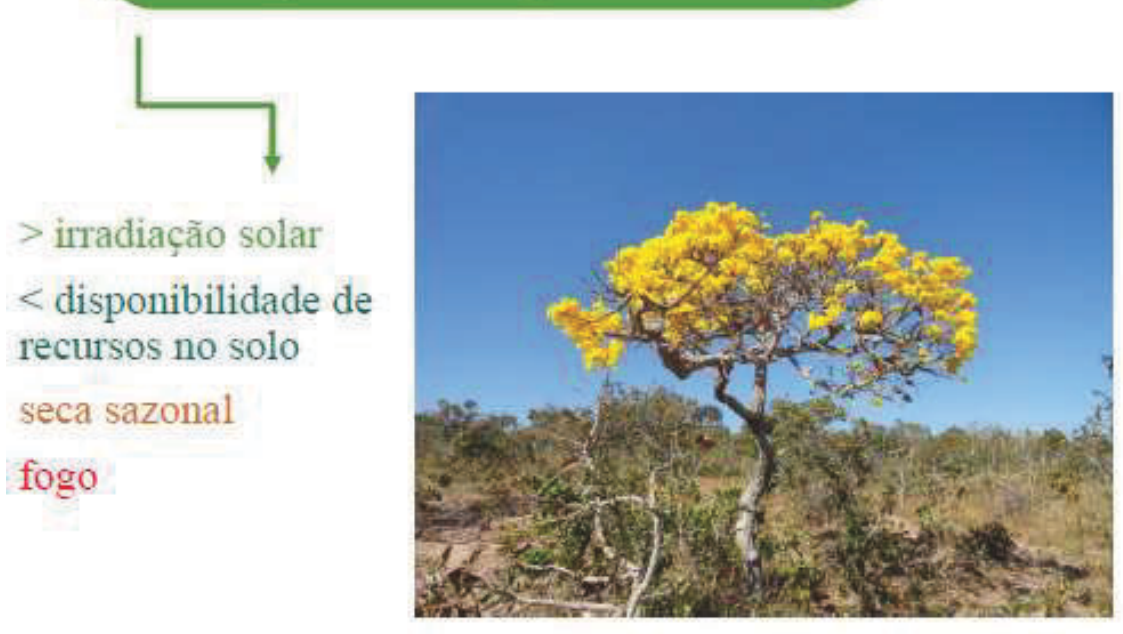

\section{Crescimento rápido}

$>$ área foliar específica

$>$ [Nmass] foliar

$>$ capacidade fotossintética

$<$ longevidade foliar

$>$ investimento em biomassa aérea

Respostas flexiveis a pulsos de nutrientes

Altas taxas de herbivoria

maximizacầ da tolerância ao sombreamento

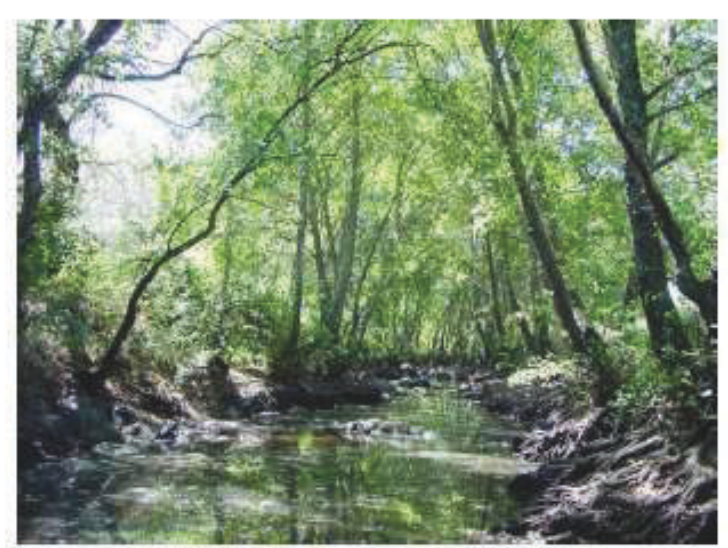

$<$ irradiação solar (sombreamento)

$>$ disponibilidade de recursos no solo

$>$ disponibilidade de água

Figura 1. Esquema contendo características morfológicas, funcionais e estratégias de alocação de recursos esperadas para espécies típicas de cerrado sensu stricto (esquerda) e de mata de galeria (direita). Baseado nos trabalhos de Coley (1985), Franco \& Haridasan (2008), Rossatto et al. (2009a, 2013) e Valladares \& Niinemets $(2008)$ [Nmass] concentração

de nitrogênio

por massa foliar. 
No mesmo ano, Franks et al. (2009) publicaram os resultados de um experimento que realizaram com Eucalyptus globulus, no qual analisaram os padrões de tamanho e densidade estomática apresentados por folhas de plântulas e rebrotas desta espécie quando plantadas em dois sítios próximos, porém diferenciados em termos de precipitação anual ${ }^{4}$ (gradiente de precipitação). A área de plantio, o número de indivíduos plantados e o espaçamento entre os mesmos foram padronizados, bem como a disponibilidade de nutrientes (adicionados junto a cada indivíduo a concentrações não limitantes). Os autores utilizaram equações básicas para difusão de gases através de estômatos e encontraram uma correlação negativa entre a densidade e o tamanho médio dos estômatos, o que oferece vantagens para a planta submetida a diferentes condições de disponibilidade hídrica, conferindo-lhe plasticidade nos valores máximos de condutância estomática de dióxido de carbono e vapor d'água ${ }^{5}$ com alterações mínimas na alocação epidérmica para estômatos, considerando que a faixa de variação de espaço epidérmico alocado para estas células especializadas costuma ser restrita pelo componente filogenético.

Adicionalmente, Franks et al. (2009) observaram: (i) uma correlação negativa entre o tamanho dos estômatos e o percentual de nitrogênio foliar no sítio de maior pluviosidade, i.e., uma tendência de que plântulas e rebrotas estabelecidas sob condições menos limitantes de disponibilidade hídrica desenvolvessem folhas com estômatos menores e maior concentração de nitrogênio (\%); (ii) correlação positiva entre a densidade de estômatos e o conteúdo foliar de nitrogênio sob alta e baixa pluviosidade; (iii) correlação negativa entre condutância estomática máxima de vapor d'água e o tamanho dos estômatos sob baixa pluviosidade; (iv) correlação

\footnotetext{
${ }^{4}$ Experimento realizado no sudoeste da Austrália, região de clima sazonal que tipicamente apresenta invernos frios e úmidos e verões quentes e secos.

${ }^{5}$ Considerando condutância estomática máxima aquela alcançada quando a planta encontra condições ótimas para a realização da fotossíntese em termos de disponibilidade hídrica, luminosa e de nutrientes.
} 
positiva significativa entre condutância estomática máxima e a densidade de estômatos sob alta e baixa pluviosidade, com coeficiente de determinação maior sob baixa pluviosidade.

A presente dissertação consiste num esforço de aprofundar e conectar os resultados encontrados por Rossatto et al. (2009b) às conclusões pós-experimentais de Franks et al. (2009), tendo como objetivo a verificação das relações entre o tamanho e densidade de estômatos, a condutância estomática máxima calculada (teórica) e o conteúdo foliar de nitrogênio e carbono em base de área para oito pares congenéricos de espécies de cerrado s.S. e de mata de galeria, pertencentes a sete famílias botânicas distintas, as quais foram amostradas em áreas transicionais entre as duas fitofisionomias.

Sublinhamos que, diferentemente de Franks et al. (2009), que observaram alterações nos padrões estomáticos e suas relações com a condutância estomática e conteúdo foliar de nitrogênio para uma única espécie ao longo de um gradiente hídrico, aqui investigamos tais padrões em pares de espécies crescendo sob as mesmas condições ambientais de precipitação e disponibilidade de nutrientes, sendo metade delas tipicamente encontradas nas matas de galeria, e a outra metade, composta por suas respectivas congêneres, típica de cerrado s.s. Consideramos que, nessas áreas de transição, as espécies de mata de galeria estariam relativamente mais limitadas em termos de disponibilidade hídrica e de nutrientes, em comparação com as espécies de cerrado (adaptadas à baixa disponibilidade de nutrientes e possivelmente dotadas de sistemas radiculares mais profundos).

Outro ponto importante é que os pares de espécies selecionados não são exatamente os mesmos que aqueles estudados por Rossatto et al. (2009b), havendo correspondência entre cinco gêneros, porém apenas um par congenérico idêntico (Vochysia thyrsoidea e Vochysia tucanorum), 
sendo que para a família Vochysiaceae investigamos um segundo par de espécies, pertencente ao gênero Qualea.

As hipóteses testadas são que, em áreas de transição cerrado s.s.-mata de galeria, (i) as espécies de cerrado devem apresentar estômatos maiores e densidades estomáticas estatisticamente similares ao grupo de mata, confirmando os padrões encontrados por Rossatto et al. (2009b), o que deve se traduzir em uma alocação epidérmica para estômatos maior para as espécies de cerrado e em médias de condutância estomática máxima calculada superiores; (ii) haverá diferenciação entre espécies de cerrado e de mata ao relacionar as médias de condutância máxima de cada grupo com o conteúdo de nitrogênio e carbono por área foliar. 


\section{MATERIAIS E MÉTODOS}

\section{Área de estudo e seleção dos pares congenéricos}

As coletas foram realizadas no Distrito Federal, nas áreas contíguas da Fazenda Água Limpa - FAL/UnB e da Reserva Ecológica do Instituto Brasileiro de Geografia e Estatística (Recor-IBGE) $)^{6}$. A Reserva tem sede entre as coordenadas geográficas $15^{\circ} 56^{\prime} \mathrm{S}$ e $47^{\circ} 52^{\prime} \mathrm{W}$, situase na cota altimétrica de 1100 metros e dista 26 quilômetros da cidade de Brasília, no sentido Sul.

A cobertura vegetal na região é composta por um mosaico de fitofisionomias de Cerrado, abrangendo formações savânicas (campo limpo, campo sujo, cerrado sensu stricto), florestais (cerradão e mata de galeria) e algumas áreas de transição savana-floresta, onde foram realizadas as coletas. A precipitação anual média para o período de $2005-2014$ foi $1363.8 \mathrm{~mm}$, sendo que os dados pluviométricos de 2015 e 2016 registrados pela estação meteorológica local não foram disponibilizados (Figura 2).

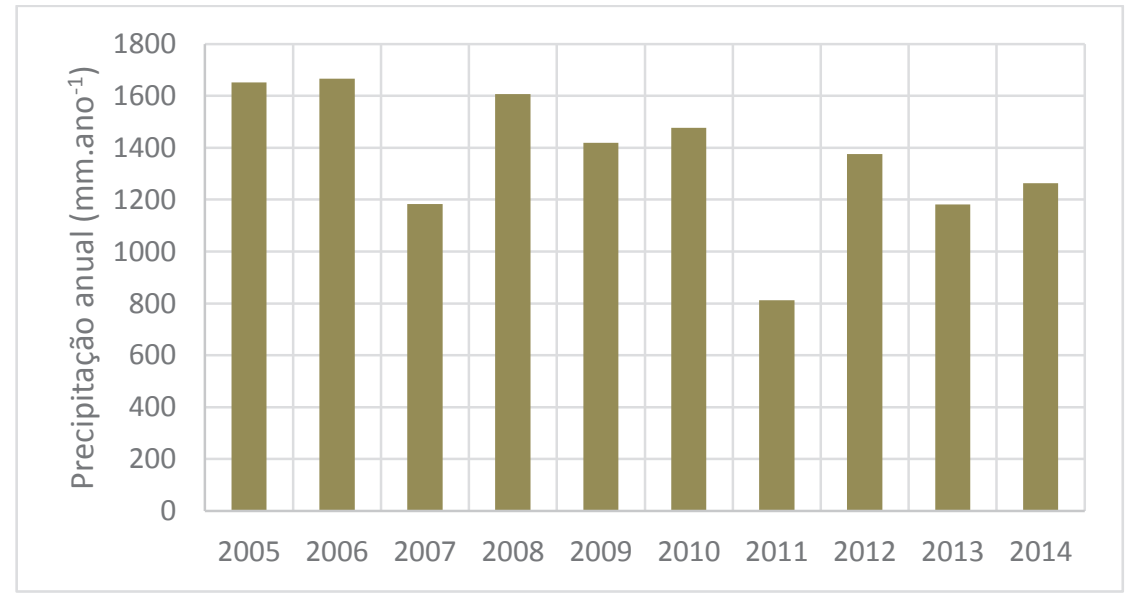

Figura 2. Precipitação anual na região de estudo para o período de 20052014. Gráfico baseado nas planilhas de dados pluviométricos disponibilizadas on line pela Recor-IBGE (http://www.recor.org.br).

\footnotetext{
${ }^{6}$ Área especialmente protegida que possui 1300 hectares de extensão, integrando parcialmente a Área de Proteção Ambiental (APA) Gama Cabeça-de-Veado e consistindo em área-núcleo da Reserva da Biosfera do Cerrado.
} 
Os pares congenéricos de espécies de mata e de cerrado que potencialmente poderiam ser encontrados na área de estudo foram selecionados mediante consulta a guias de campo regionais para identificação botânica de espécies arbóreas, os quais possuem chaves de identificação baseadas em filotaxia (Silva-Júnior 2012, Silva-Júnior \& Pereira 2009; Kuhlmann 2012) e ao inventário botânico da Recor-IBGE (Pereira et al. 2004). De posse da lista de espécies possíveis, foram realizadas as saídas de campo entre fevereiro e abril de 2016 (do meio para o final da estação chuvosa) e, conforme constatada a presença de pares e do número necessário de indivíduos por espécie, efetuamos as coletas e o georreferenciamento de suas localizações (Tabela 1).

Tabela 1. Lista de espécies estudadas e suas famílias botânicas, fitofisionomias típicas de ocorrência, data e local das coletas.

\begin{tabular}{llccc}
\hline Espécies & Família & Fitofisionomia & Coletas & Local \\
\hline Byrsonima verbascifolia (L.) DC. & Malpighiaceae & Cerrado & $24 / 02 / 2016$ & FAL-UnB \\
Byrsonima laxiflora Griseb. & Malpighiaceae & Mata & $25 / 02 / 2016$ & FAL-UnB \\
Guapira noxia Netto (Lundell) & Nyctaginaceae & Cerrado & $25 / 02 / 2016$ & Recor-IBGE \\
Guapira graciliflora (Mart. ex Schmidt) & Nyctaginaceae & Mata & $25 / 02 / 2016$ & Recor-IBGE \\
Hymenaea stigonocarpa Mart. ex Hayne & Fabaceae-Caesalpinoideae & Cerrado & $20 / 04 / 2016$ & Recor-IBGE \\
Hymenaea courbaril L. & Fabaceae-Caesalpinoideae & Mata & $20 / 04 / 2016$ & Recor-IBGE \\
Pouteria ramiflora (Mart.) Radlk. & Sapotaceae & Cerrado & $20 / 04 / 2016$ & Recor-IBGE \\
Pouteria torta (Mart.) Radlk. & Sapotaceae & Mata & $20 / 04 / 2016$ & Recor-IBGE \\
Qualea parviflora Mart. & Vochysiaceae & Cerrado & $24 / 02 / 2016$ & FAL-UnB \\
Qualea dichotoma (Warm.) Stafl. & Vochysiaceae & Mata & $24 / 02 / 2016$ & FAL-UnB \\
Tabebuia chrysotricha Mart. ex DC. & Bignoniaceae & Cerrado & $20 / 04 / 2016$ & FAL-UnB \\
Tabebuia impetiginosa Standl. & Bignoniaceae & Mata & $20 / 04 / 2016$ & Recor-IBGE \\
Vochysia thyrsoidea Pohl. & Vochysiaceae & Cerrado & $24 / 02 / 2016$ & FAL-UnB \\
Vochysia tucanorum Mart. & Vochysiaceae & Mata & $25 / 02 / 2016$ & Recor-IBGE \\
Xylopia aromática (Lam.) Mart. & Annonaceae & Cerrado & $24 / 02 / 2016$ & FAL-UnB \\
Xylopia brasiliensis Spreng. & Annonaceae & Mata & $20 / 04 / 2016$ & Recor-IBGE \\
\hline \hline
\end{tabular}




\section{Coleta das amostras para análises anatômicas, morfológicas e nutricionais}

No campo, três indivíduos por espécie foram identificados e georreferenciados, totalizando 48 indivíduos de 16 espécies. Visando a padronização metodológica, foram coletadas folhas de sol, isto é, mais expostas à luminosidade na maior parte do dia, completamente expandidas, sem sinais de senescência ou danos, as quais foram selecionadas entre o segundo e quarto nós de cada ramo.

O material foi armazenado em sacos plásticos transparentes, dentro dos quais colocamos um pouco de água para manter as folhas úmidas. Os sacos foram etiquetados e identificados, sendo que coletamos, adicionalmente, dois ramos foliares de cada indivíduo para a posterior confecção e depósito de exsicatas no Herbário da Universidade de Brasília e no Herbário da Reserva Ecológica do Roncador (RECOR-IBGE). As coletas foram efetuadas levando em consideração o número de folhas necessárias para as análises estatísticas, sendo coletadas cinco folhas por indivíduo para as análises dos complexos estomáticos (seções paradérmicas) e outras 10 folhas para determinar a concentração foliar de nitrogênio e carbono e a área foliar específica ${ }^{7}$. As três análises requisitaram, portanto, 15 folhas por indivíduo, totalizando 720 folhas.

\footnotetext{
${ }^{7}$ É fundamental considerar, no planejamento das atividades, a duração das atividades em campo e a quantidade máxima de material a ser coletado por dia, já que após as coletas o material fresco precisa ser organizado no laboratório o quanto antes e conforme a metodologia de cada análise. Também é recomendável coletar um número um pouco maior de folhas do que o tamanho amostral definido para cada procedimento, uma vez que, havendo perdas de material, torna-se necessário voltar ao campo e realizar nova coleta (dependendo da época do ano e da espécie, no caso do Cerrado, pode não haver folhas).
} 
Obtenção das epidermes, análise dos complexos estomáticos e cálculo das condutâncias estomáticas máximas

Para as análises dos complexos estomáticos, foram adotadas técnicas usuais em anatomia vegetal (Johansen 1940). Extraímos fragmentos medianos de cada folha fresca, incluindo a nervura central, e os mesmos foram fixados em FAA 70\% (formaldeído 37\%, $50 \mathrm{~mL}$; etanol a 70\%, $50 \mathrm{~mL}$; ácido acético glacial, $900 \mathrm{~mL}$ ) por 24-48 horas, sendo em seguida armazenados em álcool 50\% para posterior análise. Os fragmentos foram armazenados em frascos de vidro identificados com etiquetas conforme a espécie e indivíduo a que pertenciam.

O método utilizado para a extração das epidermes foi o de maceração de tecidos com a solução ácida de Franklin (ácido acético glacial e peróxido de hidrogênio, em proporção 1:1), a qual digere o mesofilo das folhas e permite a dissociação e obtenção das epidermes adaxial e abaxial. As amostras foliares foram retiradas do álcool 50\%, reidratadas em água destilada, cortadas em fragmentos de aproximadamente $1 \mathrm{~cm}^{2}$ e então embebidas na referida solução, em pequenos frascos de vidro identificados por espécie e indivíduo e cobertos com papel alumínio, os quais foram levados à estufa a $60^{\circ} \mathrm{C}$ por 3 a 5 dias (tempo variável conforme a espécie). Conforme o material adquiria aspecto esbranquiçado e mole, identificava-se o momento de seguir à próxima etapa do procedimento, que consiste em retirá-lo da solução de Franklin e lavá-lo em água destilada, separando os fragmentos foliares por indivíduo em diferentes placas de Petri $^{8}$ e removendo cuidadosamente os mesofilos com auxílio de dois pinceis chatos $\mathrm{n}^{\mathrm{o}}$ 815-02.

\footnotetext{
${ }^{8}$ Nessa fase também é importante adequar o tempo disponível em laboratório à quantidade de material a ser processada por dia. Nesse estudo, considerando a necessidade de ter cinco seções epidérmicas examináveis por indivíduo (considerando que nem todas as lâminas microscópicas ficam suficientemente boas para o registro fotográfico e análise dos parâmetros estomáticos), montamos cinco lâminas por indivíduo contendo duas seções epidérmicas de folhas diferentes do mesmo indivíduo. Num período de 8-9 horas seguidas de trabalho em laboratório, era possível montar 30 lâminas, isto é, aprontar o material anatômico referente a duas espécies por dia. É importante atentar para este ponto porque, iniciado o processo, sua interrupção pode resultar em perdas de material que podem comprometer o trabalho.
} 
Em seguida, para cada indivíduo, procedemos com a imersão das folhas em álcool 30 ou $40 \%$ e coloração em solução de safranina $1 \%$, submetendo-as posteriormente a uma sequência crescente de concentrações de álcool etílico $(50 \%, 70 \%, 90 \%, 100 \%$, permanecendo entre 3 minutos em cada etapa e 5 minutos na última, a qual é realizada duas vezes), visando garantir uma boa infiltração, considerando que o meio de montagem de lâminas adotado foi o Verniz Vitral incolor $500 \circledR$ (alcoólico). Entre a sequência de desidratação alcoólica e a montagem das lâminas, as epidermes foram submetidas a uma bateria de imersão em álcool e acetato de butila, seguindo a sequência de concentrações de $3: 1,1: 1,1: 3$ e acetato puro.

Logo após a montagem, as lâminas foram dispostas em local seguro para secarem à temperatura ambiente, e após secas, armazenadas em caixas apropriadas. As análises e fotografias das lâminas foram realizadas por meio de um microscópio óptico Leica DM750 acoplado a uma câmera digital Leica ICC50 HD, sendo o equipamento disponibilizado pelo Laboratório de Fisiologia do Estresse em Plantas, vinculado ao Departamento de Botânica da Universidade de Brasília (UnB). O software utilizado para o registro fotográfico, a determinação do comprimento e largura das células-guarda foi o Leica Application Suite (LAS EZ) versão 3.2.1, e para a determinação da densidade estomática, o AnatiQuanti versão 2.0, disponibilizado gratuitamente pelo Laboratório de Anatomia Vegetal da Universidade Federal de Viçosa.

As medidas estomáticas foram tomadas sob a amplificação microscópica de 40x, tendo sido medidos 20 complexos estomáticos (pares de células-guarda) por folha, sendo 5 estômatos por campo de visão, quatro campos de visão por folha, cinco folhas por indivíduo e três indivíduos por espécie, totalizando 960 campos de visão (micrografias) de 336 × $252 \mu \mathrm{m}\left(\sim 0,0085 \mathrm{~mm}^{2}\right)$ e 4800 complexos estomáticos medidos. A densidade estomática foi calculada, para cada indivíduo, como las imediatamente, elas podem ser rearmazenadas em álcool $50 \%$. 
a média do número de estômatos contados nos mesmos campos de visão registrados anteriormente, e posteriormente foram estimadas as densidades, comprimentos e largura estomáticos médios por espécie ( $n=3$ indivíduos por espécie) e por grupo funcional ( $n=8$ espécies por grupo funcional). Os parâmetros medidos foram comprimento da célula-guarda ("L" em $\mu \mathrm{m}$ ), largura do par de célulasguarda ("W", em $\mu \mathrm{m}$ ), tamanho do estômato ("S", estimado como $\mathrm{S}=\mathrm{L} * \mathrm{~W}$, conforme a metodologia de Franks et al. 2009 e Franks et al. 2012) e área máxima do poro estomático ("a em $\mu \mathrm{m}^{2}$ ). A área máxima do poro estomático foi calculada como $\mathrm{a}_{\max }=\alpha * \mathrm{~S}$, sendo $\alpha=0.12$, conforme Franks \& Beerling (2009).

A condutância estomática máxima de vapor d'água (" $\mathrm{g}_{\mathrm{wmax}}$ ", em mol $\left.\mathrm{m}^{-2} \mathrm{~s}^{-1}\right)$ foi estimada como $\mathbf{g}_{\mathbf{w m a x}}=\frac{(\boldsymbol{d} \times \boldsymbol{D} \times \boldsymbol{a m a x})}{v \times\left(\boldsymbol{l}+\frac{\pi}{2} \times \sqrt{\frac{a m a x}{\pi}}\right)}$, sendo "d" a difusividade da molécula de água no ar $\left(2.57 \times 10^{-5} \mathrm{~m}^{2}\right.$ $\left.\mathrm{s}^{-1}\right)$, “D” a densidade estomática ( $\mathrm{n}^{\mathrm{o}}$ de estômatos por $\mathrm{m}^{2}$ ), "a $\mathrm{a}_{\max }$ " a área máxima do poro estomático $\left(\mathrm{m}^{2}\right)$, “v" o volume molar do ar $\left(0.022413968 \mathrm{~m}^{3} \mathrm{~mol}^{-1}\right)$ e "l" a profundidade do poro estomático (em metros, aproximada como a metade da largura da célula-guarda, W/2, e equivalendo ao raio da circunferência para células-guarda totalmente infladas), conforme Franks et al. $(2009,2012)$. A condutância estomática máxima de $\mathrm{CO}_{2}$, " $\mathrm{g}_{\mathrm{cmax}}$ ", foi calculada como $\mathrm{g}_{\mathrm{wmax}} / 1.6$ (Farquhar \& Sharkey 1982 apud Franks et al. 2009). Por fim, a alocação epidérmica para estômatos foi calculada por meio do Índice de Área do Poro Estomático (Stomatal Pore Area Index, SPI), sendo SPI $=\mathrm{L}^{2} * \mathrm{D}$.

\section{Área Foliar Especifica}

As medições de área foliar específica foram realizadas previamente à análise de carbono e nitrogênio, com as mesmas folhas. Para determinação da razão média entre a área e a massa seca foliar, foram extraídos, com auxílio de um furador metálico de $4 \mathrm{~mm}$ de raio, dois discos circulares por folha, um de cada lado do limbo, com área padronizada (área do disco $=\pi \mathrm{r}^{2}$ ), sempre na região 
central das folhas. Cada folha e seus respectivos discos foram secos em estufa a $60^{\circ} \mathrm{C}$, por três dias, passando pela posterior pesagem em balança de precisão $( \pm 0.001 \mathrm{~g})$. Em seguida, calculamos a razão entre a área padrão do disco e a massa seca média dos discos extraídos por folha, obtendo posteriormente as médias individuais e a área foliar específica média por espécie ("SLA", em $\mathrm{cm}^{2} / \mathrm{g}$ ) e por grupo funcional (mata ou cerrado).

\section{Análises de nitrogênio e carbono}

As folhas coletadas para a determinação do conteúdo de nitrogênio e carbono por área foliar (10 folhas por indivíduo, 3 indivíduos por espécie) passaram pelo processo de secagem na estufa a $60^{\circ} \mathrm{C}$ por 3 dias, e posterior moagem em moinho microvibratório (FRITSCH Analysette 3 SPARTAN Pulverisette 0), até que adquirissem granulação bem fina, o que no caso de algumas espécies demorou cerca de 1,5 hora por indivíduo. Em seguida, preparamos as amostras combinadas de cada indivíduo, embrulhando-as em folhas metálicas de tamanho e massa padronizados, e realizamos a pesagem individual em balança de precisão, a qual é acoplada ao microcomputador que processa os dados gerados pelo analisador de carbono e nitrogênio por combustão (Leco CN 628). Preparadas as amostras e registradas as suas respectivas massas e ordem de medição, prosseguimos com a inserção das mesmas no Analisador de $\mathrm{CN}$ e à geração dos dados de concentração desses elementos.

\section{Análises Estatisticas}

O software R Studio versão 1.0.44 foi usado para todas as análises estatísticas. Realizamos o teste de normalidade de Shapiro-Wilk para todas as variáveis medidas ou calculadas a posteriori. Os efeitos do gênero (componente filogenético) e do habitat de origem típico ou grupo funcional (cerrado ou mata) sobre a variação nos parâmetros estomáticos e morfofisiológicos foram determinados por meio de Análise Multivariada de Variância (MANOVA Two Way) para todas as 
espécies e variáveis simultaneamente, após a qual procedemos com Análises Univariadas de Variância (ANOVAs Two Way) a fim de testar os efeitos individuais de cada variável, também considerando os efeitos de gênero (fator aleatório), grupo (fator fixo) e a interação entre ambos.

Para testar diferenças entre as médias de cada variável para cada um dos pares congenéricos de mata e de cerrado, realizamos testes t pareados. Por fim, com o objetivo de estimar linhas alométricas de melhor ajuste para as relações bivariadas entre os parâmetros medidos e/ou calculados, procedemos com Análises de Eixo Principal Padronizado (Standardised Major Axis Estimation and Testing Routines, SMATRs) acompanhadas de testes para verificação de diferenças de inclinação (slopes) entre os grupos funcionais. Diferentemente da técnica de regressão linear simples, que estima uma variável a partir da outra, as SMAs estimam uma linha de melhor ajuste aos dados, de modo que a relação não se altera caso os eixos sejam invertidos (Warton et al. 2012).

Em todas as análises, diferenças foram consideradas significativas quando $P<0.05$. 


\section{RESULTADOS}

À exceção de Hymenaea stigonocarpa ${ }^{9}$, que apresentou estômatos em ambas as faces epidérmicas foliares (maior densidade na face abaxial), as demais espécies apresentaram folhas hipostomáticas e estômatos anomocíticos ou paracíticos (Figuras 3-4). O comprimento da célulaguarda (L) variou entre 17 e $43 \mu \mathrm{m}$, com médias de 28 e $21 \mu \mathrm{m}$ para espécies de cerrado e de mata, respectivamente. A largura do par de células-guarda (W) variou entre 12 e $27 \mu \mathrm{m}$, com médias de $20 \mu \mathrm{m}$ (cerrado) e $15 \mu \mathrm{m}$ (mata). O tamanho estomático $(\mathrm{S}=\mathrm{L} * \mathrm{~W})$ variou de 228 a $1201 \mu \mathrm{m}^{2}$, com médias de $616 \mu \mathrm{m}^{2}$ (cerrado) e $343 \mu \mathrm{m}^{2}$ (mata). A densidade estomática (D) apresentou valores entre 124 e 632 estômatos por mm² $^{2}$, com médias de 373 (cerrado) e 360 estômatos por mm² (mata) (Tabela 2). A espécie Guapira noxia (cerrado) apresentou os maiores valores de L, W e S, e a menor densidade estomática, enquanto as espécies de mata apresentaram os menores valores de L (Hymenaea courbaril), W (Xylopia brasiliensis) e S (Byrsonima laxiflora) e o maior valor observado para D (H. courbaril) (ANEXO).

Em média, as espécies de cerrado estudadas apresentaram valores mais elevados para o tamanho estomático $(\mathrm{S})$, condutância estomática máxima de vapor d'água $\left(\mathrm{g}_{\mathrm{wmax}}\right)$ e índice de área do poro estomático (SPI) em relação às espécies de mata $(P<0.05)$, ao passo que a densidade estomática foi estatisticamente similar entre os dois grupos (Tabela 2, Figuras 5-6). As espécies de mata apresentaram maior área foliar específica em relação às espécies de cerrado $(P<0.05)$, sendo que para as concentrações de nitrogênio $(\mathrm{N})$ e carbono $(\mathrm{C})$ por área foliar, não encontramos diferenças estatisticamente significativas entre os grupos (Tabela 2, Figura 7).

\footnotetext{
${ }^{9}$ Hymenaea stigonocarpa, popularmente conhecida como jatobá-do-cerrado, foi a única espécie que apresentou estômatos em ambas as faces epidérmicas foliares. Neste trabalho, consideramos apenas a face abaxial das folhas. A densidade estomática da face adaxial de H. stigonocarpa não foi calculada neste trabalho, importando salientar que é notoriamente menor em relação à face abaxial. Trabalhando com a mesma espécie e na mesma região de estudo, Rossato et al. (2009b) encontraram uma razão média de 7,47 $\pm 2,28$ (média \pm desvio padrão) estômatos na face abaxial em relação à adaxial.
} 
MANOVA - O resultado da Análise Multivariada de Variância indicou variação significativa nos parâmetros estomáticos, na condutância estomática máxima de vapor d'água calculada, na concentração foliar de nitrogênio e carbono em base de área e na área foliar específica analisados conjuntamente, tanto para o fator grupo funcional $(\mathrm{F}=9.59, P<0.001)$, como para gênero $(\mathrm{F}=3.65, P<0.001)$ e para a interação grupo x gênero $(\mathrm{F}=6.98, P<0.001$, Tabela 3).

Tabela 2. Amplitudes e médias por grupo para os dados de comprimento da célula-guarda (L), largura do par de células-guarda (W), tamanho estomático (S), densidade estomática (D), condutância estomática máxima de vapor d'água $\left(\mathrm{g}_{\mathrm{wmax}}\right)$, índice de área do poro estomático (SPI), área foliar específica (SLA), concentração de carbono (C) e nitrogênio $(\mathrm{N})$ por área foliar. Diferenças significativas entre grupos indicadas por asteriscos $(* * *$ para $P<0.0001$, ** para $P<0.001$, * para $P<0.05$ ).

\begin{tabular}{|c|c|c|c|}
\hline Parâmetro & Amplitude & Cerrado & Mata \\
\hline $\mathrm{L}(\mu \mathrm{m})^{* * *}$ & $17 \leq \mathrm{L} \leq 43$ & $28.97 \pm 7.01$ & $21.94 \pm 3.70$ \\
\hline $\mathrm{W}(\mu \mathrm{m})^{* * *}$ & $12 \leq \mathrm{W} \leq 43$ & $20.57 \pm 3.83$ & $15.25 \pm 3.25$ \\
\hline $\mathrm{S}\left(\mu \mathrm{m}^{2}\right) * * *$ & $228 \leq \mathrm{S} \leq 1201$ & $616.83 \pm 275.04$ & $343.54 \pm 128.76$ \\
\hline $\mathrm{D}\left(\mathrm{mm}^{-2}\right)$ & $124 \leq \mathrm{D} \leq 632$ & $373.34 \pm 159.52$ & $360.50 \pm 135.0$ \\
\hline$g_{\mathrm{wmax}}\left(\mathrm{mol} \cdot \mathrm{m}^{-2} \cdot \mathrm{s}^{-1}\right) *$ & $0.75 \leq \mathrm{g}_{\mathrm{wmax}} \leq 2.61$ & $1.63 \pm 0.6$ & $1.25 \pm 0.52$ \\
\hline SPI*** & $0.06 \leq \mathrm{SPI} \leq 0.39$ & $0.20 \pm 0.09$ & $0.13 \pm 0.08$ \\
\hline $\operatorname{SLA}\left(\mathrm{cm}^{2} \mathrm{~g}^{-1}\right) * * *$ & $45 \leq \mathrm{SLA} \leq 136$ & $66.0 \pm 11.56$ & $89.69 \pm 25.08$ \\
\hline $\mathrm{N}\left(\mu \mathrm{g} \cdot \mathrm{mm}^{-2}\right)$ & $0.91 \leq \mathrm{N} \leq 3.82$ & $1.85 \pm 0.84$ & $1.89 \pm 0.89$ \\
\hline $\mathrm{C}\left(\mu \mathrm{g} \cdot \mathrm{mm}^{-2}\right)$ & $45 \leq \mathrm{C} \leq 54$ & $50.38 \pm 3.22$ & $49.43 \pm 3.48$ \\
\hline
\end{tabular}

Tabela 3. Análise Multivariada de Variância (MANOVA) para efeitos de grupo funcional (mata/cerrado) e gênero, incluindo a interação grupo x gênero. Diferenças significativas apontadas por asteriscos $(* * *$ quando $P$ $<0.0001$, ** quando $P<0.001$, * quando $P<0.05$ ).

\begin{tabular}{lccc}
\hline Fonte de Variação & Df & F-value & P-value \\
\hline Grupo Funcional & 1 & 9.5919 & $<0.0001 * *$ \\
Gênero & 7 & 3.6527 & $<0.001 * *$ \\
Grupo Funcional x Gênero & 7 & 6.982 & $<0.0001 * * *$ \\
\hline
\end{tabular}




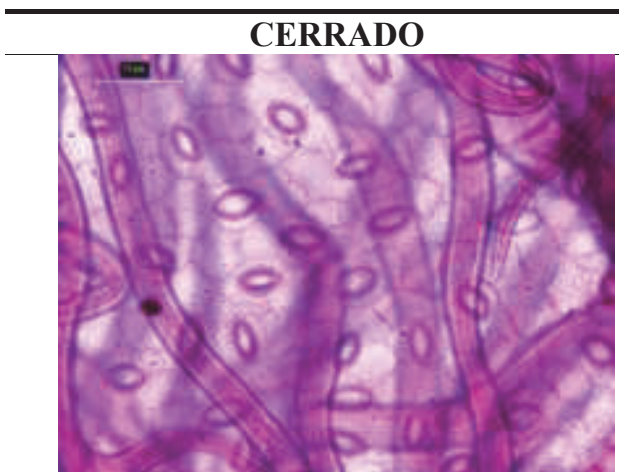

Byrsonima verbascifolia

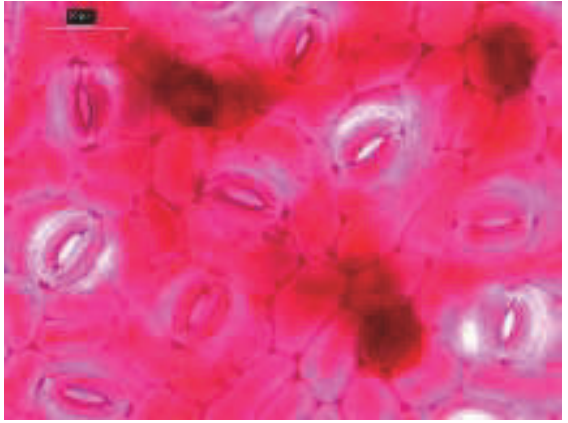

Guapira noxia

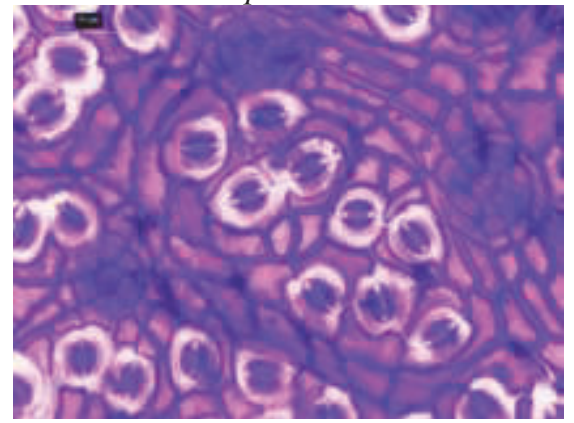

Hymenaea stigonocarpa

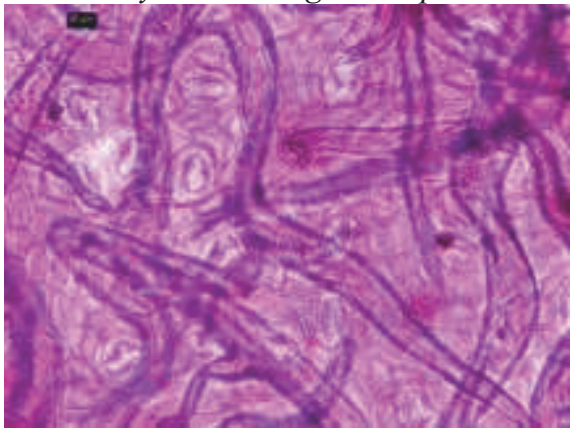

Pouteria ramiflora
MATA

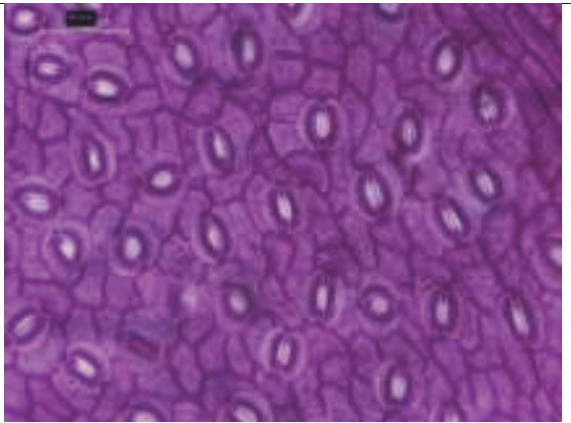

Byrsonima laxiflora

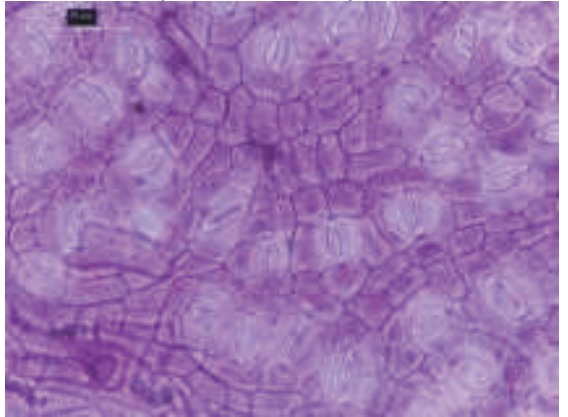

Guapira graciliflora

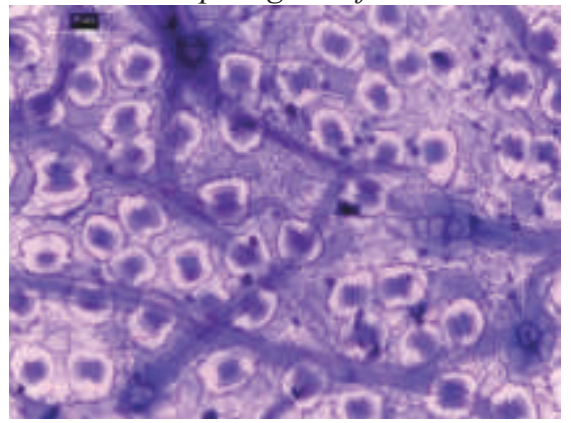

Hymenaea courbaril

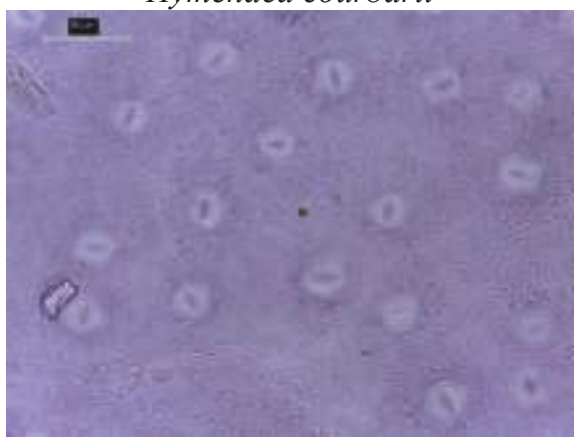

Pouteria torta

Figura 3. Micrografias das epidermes foliares abaxiais das espécies, organizadas por pares congenéricos e por grupo. Para Byrsonima, Guapira, Hymenaea e Pouteria, as espécies de cerrado apresentaram estômatos maiores em relação as espécies de mata $(P<0.05)$. Densidades estomáticas semelhantes entre espécies de cerrado e mata para Byrsonima e Pouteria, e maiores para espécies de mata em Guapira e Hymenaea $(P<0.05)$. Barra de escala $=50 \mu \mathrm{m}$. 


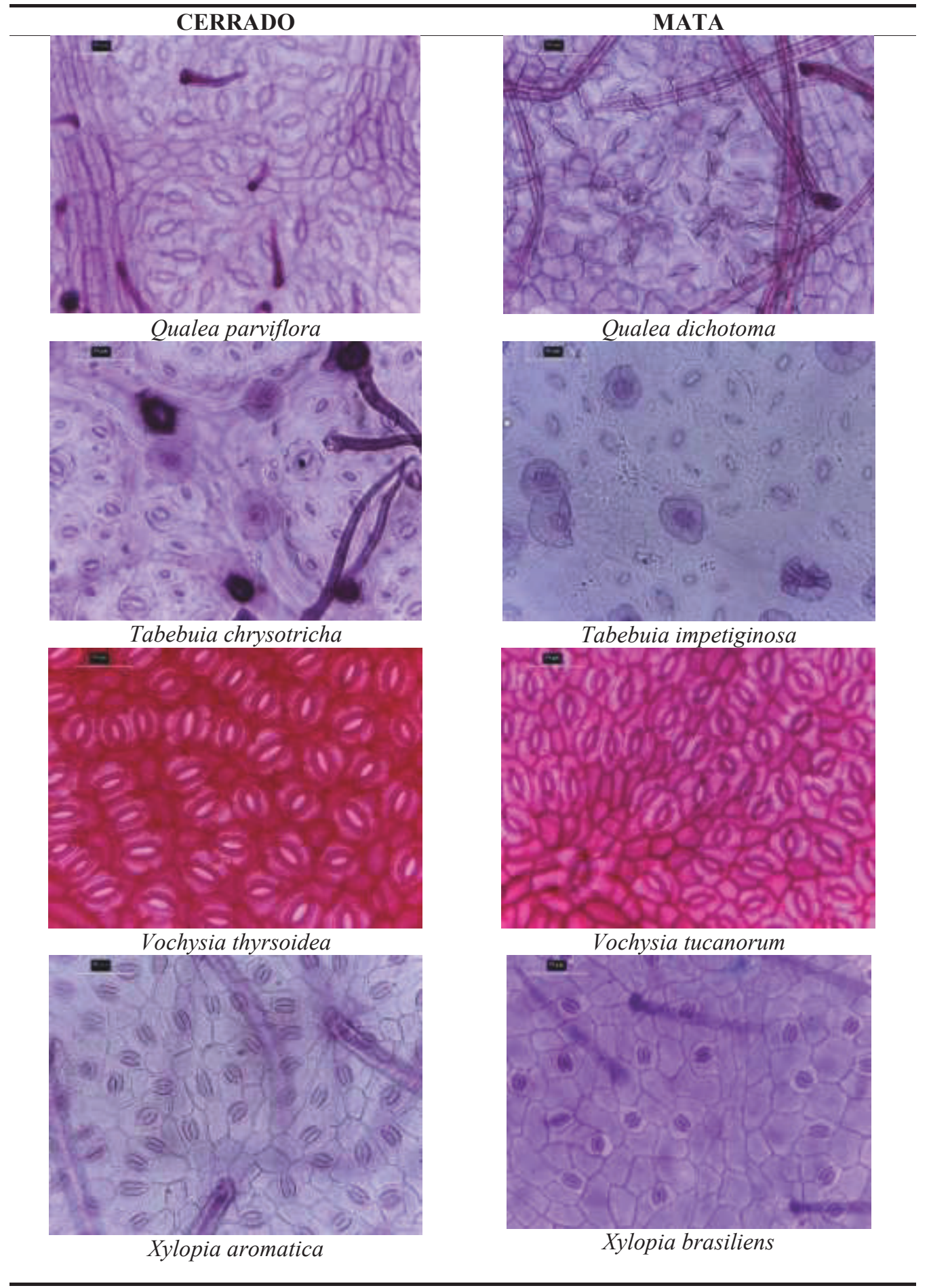

\begin{abstract}
Figura 4. Micrografias das epidermes foliares abaxiais das espécies, organizadas por pares congenéricos e por grupo, para os gêneros Qualea, Tabebuia, Vochysia e Xylopia. Para Qualea, a espécie de cerrado apresentou maior densidade estomática e tamanho estomático similar à espécie de mata $(P<0.05)$. Para Tabebuia e Vochysia, as espécies de cerrado e mata apresentaram tamanhos e densidades estomáticas similares $(P<0.05)$. Para Xylopia, a espécie de cerrado apresentou maior tamanho e maior densidade em relação à congênere de mata $(P<0.05)$. Barra de escala $=50 \mu \mathrm{m}$.
\end{abstract}


A

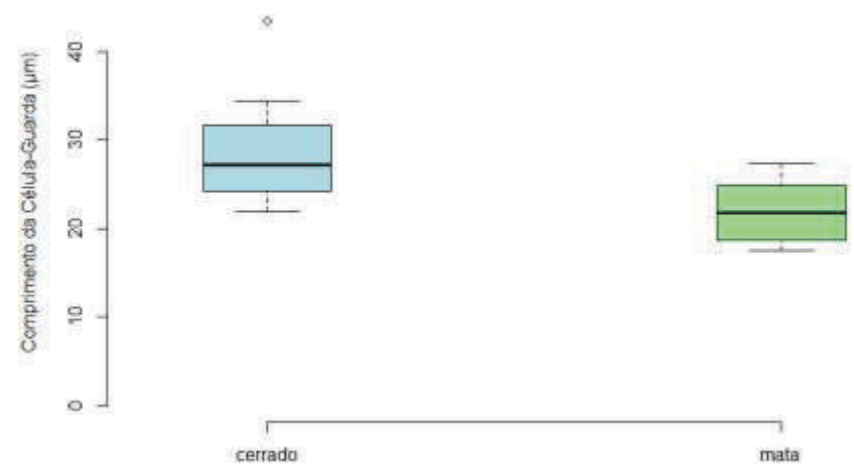

$\mathrm{B}$

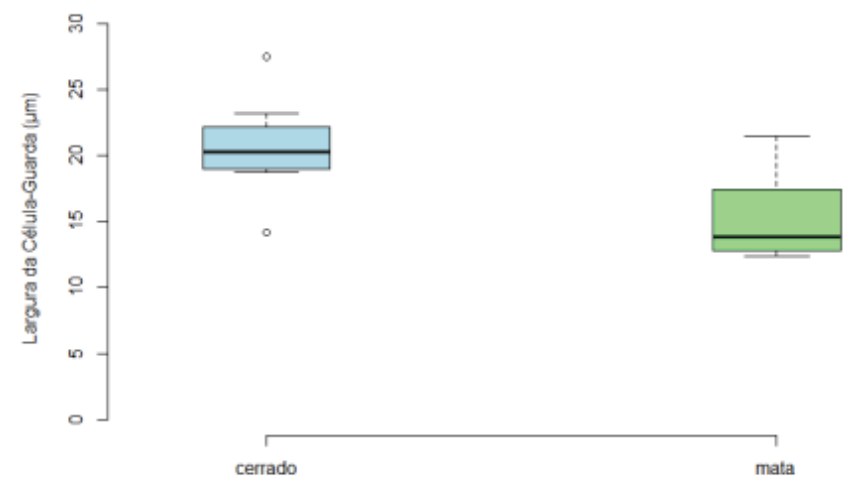

C

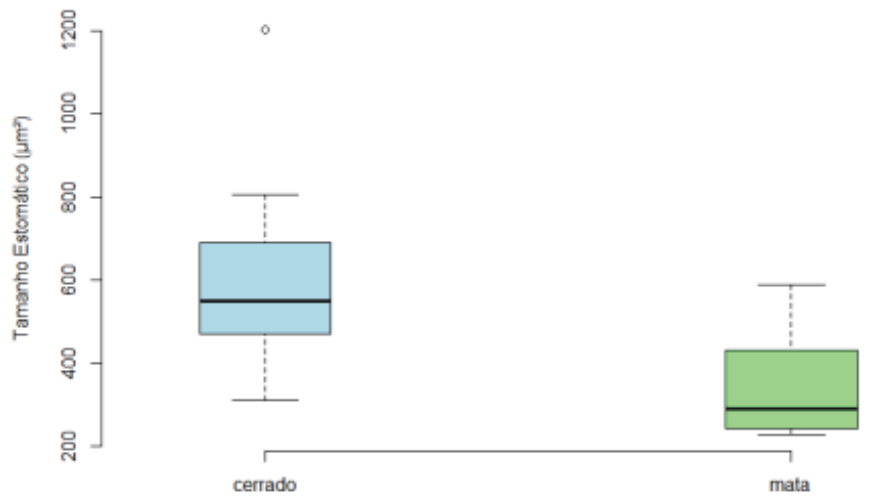

Figura 5. Amplitude de variação no comprimento da célula-guarda (A), largura do par de células-guarda (B) e tamanho estomático (C) para os conjuntos de espécies de cerrado e de mata. Em todos os gráficos, o outlier superior entre as espécies de cerrado corresponde a Guapira noxia, e em (B) o outlier inferior corresponde a Xylopia aromatica. Diferenças estatisticamente significativas entre os grupos foram encontradas para todos os parâmetros $(P<0.05)$. 
A

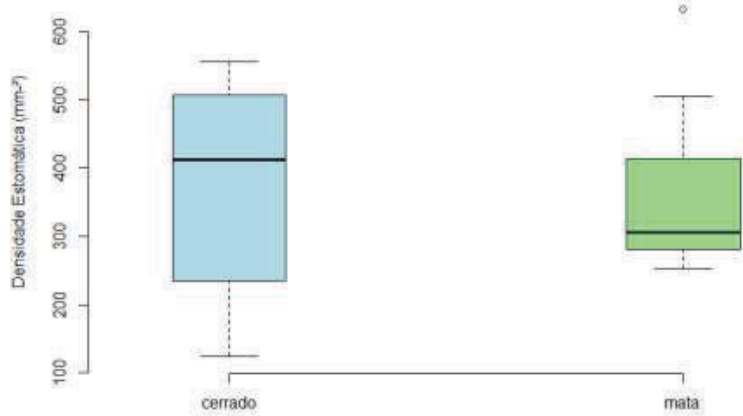

B

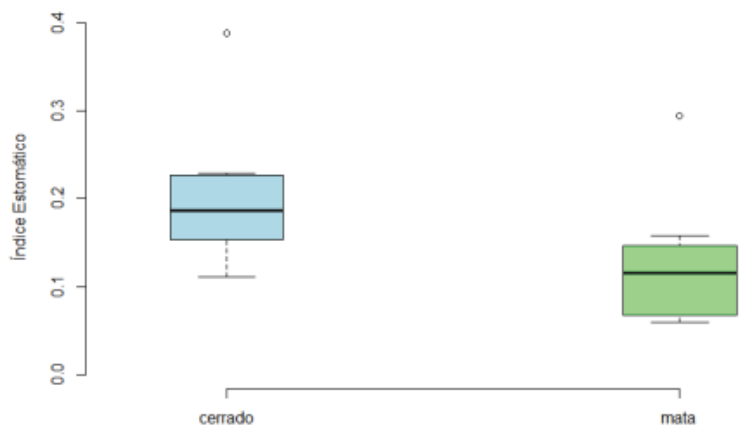

C

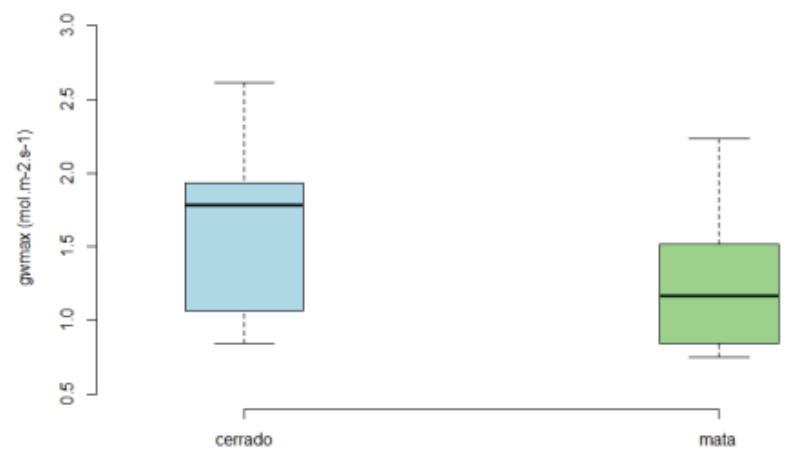

Figura 6. Amplitude de variação na densidade estomática (A), índice de área do poro estomático (B) e condutância máxima de vapor d'água (C) para espécies de cerrado e de mata. Em (A), o outlier superior das entre as espécies de mata corresponde a Hymenaea courbaril. Os outliers superiores para o índice estomático correspondem a Vochysia thyrsoidea (cerrado) e Vochysia tucanorum (mata). Diferenças estatisticamente significativas entre grupos foram encontradas apenas para o índice de área do poro estomático e a condutância estomática máxima, " $\mathrm{g}_{\mathrm{wmax}}$ " $(P<0.05)$. 
A

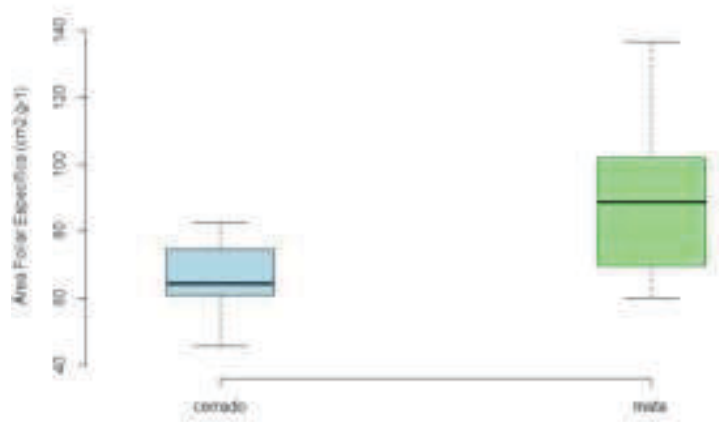

B

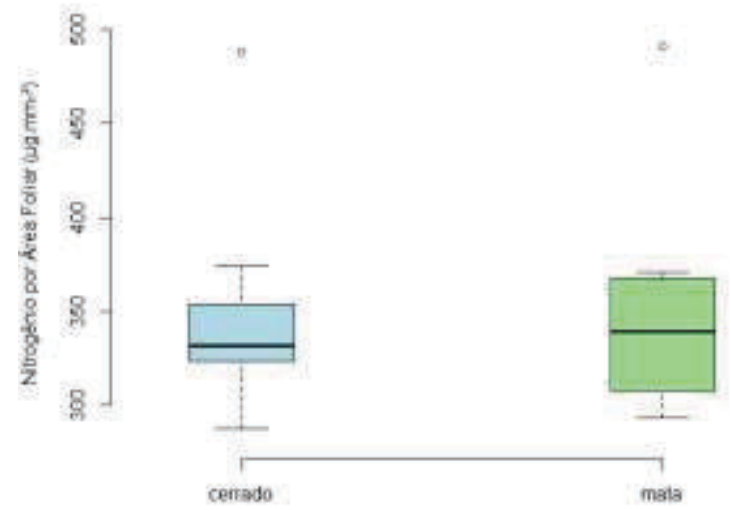

C

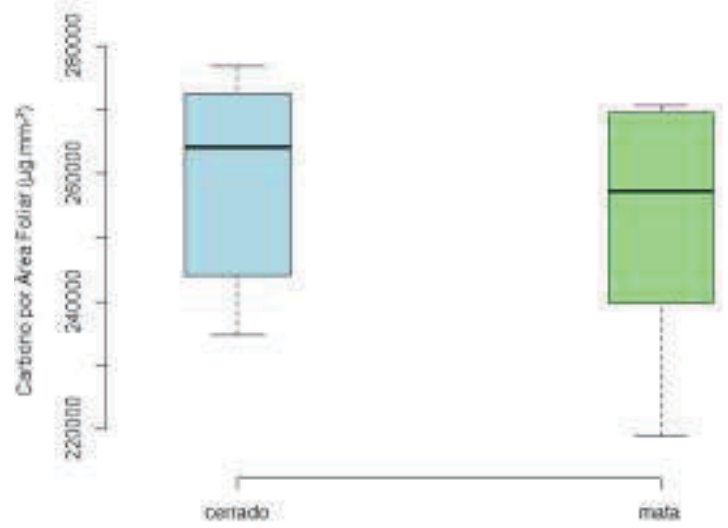

Figura 7. Amplitude de variação na área foliar específica (A), concentração de nitrogênio por área foliar (B) e concentração de carbono por área foliar (C) para espécies de cerrado e de mata. Os outliers superiores para a concentração de nitrogênio por área foliar correspondem a Guapira noxia (cerrado) e Guapira graciliflora (mata). Diferenças estatisticamente significativas entre grupos foram encontradas apenas para a área foliar específica $(P<0.05)$. 
ANOVAs FATORIAIS - Os resultados das Análises Univariadas de Variância apontaram contribuição individual significativa, em termos de grupo, gênero e da interação entre ambos, do comprimento e largura médios da célula-guarda ( $\mathrm{L}$ e W, respectivamente), tamanho do estômato (S), área máxima do poro estomático $\left(\mathrm{a}_{\max }\right)$, condutância estomática máxima de vapor d'água $\left(\mathrm{g}_{\mathrm{wmax}}\right)$, índice de área do poro estomático (SPI) e área foliar específica (SLA). As concentrações foliares de nitrogênio $(\mathrm{N})$ e carbono (C) por área foliar e a densidade estomática também contribuíram significativamente com o resultado considerando o fator gênero e a interação grupo x gênero, não tendo sido significativas apenas quando analisadas para o fator grupo funcional isoladamente (Tabela 4).

TESTES T PAREADOS - A interação grupo x gênero ficou evidente quando examinamos os pares congenéricos individualmente. Os testes pareados para verificação de diferenças entre as espécies que compõem cada par congenérico indicaram que os tamanhos estomáticos foram maiores para as espécies típicas de cerrado (Byrsonima, Guapira, Hymenaea, Pouteria e Xylopia) ou similares entre espécies de cerrado e mata (Qualea, Tabebuia e Vochysia). A densidade estomática foi similar para quatro pares congenéricos (Byrsonima, Pouteria, Tabebuia e Vochysia), maior para espécies de cerrado no caso de Qualea e Xylopia e maior para espécies de mata em Guapira e Hymenaea (Tabela 5 e ANEXO).

O índice de área do poro estomático, medida parcial de alocação epidérmica para estômatos uma vez que combina o comprimento da célula-guarda e a densidade estomática $\left(\mathrm{SPI}=\mathrm{L}^{2} * \mathrm{D}\right)$, foi maior para as espécies de cerrado no caso de três pares congenéricos (Byrsonima, Qualea e Xylopia) ou similar para os outros cinco pares (Guapira, Hymenaea, Pouteria, Tabebuia e Vochysia) (Tabela 5 e ANEXO). 
Tabela 4. Análises univariadas de variância (ANOVAs fatoriais) para cada variável estudada, considerando os fatores grupo funcional, gênero e a interação grupo x gênero. Diferenças significativas apontadas por asteriscos (*** para $P<0.0001$, ** para $P<0.001$, * para $P<0.05$ ).

\section{Fonte de Variação}

Df

F-value

P-value

\section{Grupo Funcional}

$\mathrm{L}(\mu \mathrm{m})$

$\mathrm{W}(\mu \mathrm{m})$

$\mathrm{D}\left(\mathrm{mm}^{-2}\right)$

$\mathrm{S}\left(\mu \mathrm{m}^{2}\right)$

$\mathrm{a}_{\max }\left(\mu \mathrm{m}^{2}\right)$

$\mathrm{g}_{\mathrm{wmax}}\left(\mathrm{mol} \cdot \mathrm{m}^{-2} \cdot \mathrm{s}^{-1}\right)$

SPI

$\operatorname{SLA}\left(\mathrm{cm}^{2} \mathrm{~g}^{-1}\right)$

$\mathrm{N}\left(\mu \mathrm{g} \cdot \mathrm{mm}^{-2}\right)$

$\mathrm{C}\left(\mu \mathrm{g} \cdot \mathrm{mm}^{-2}\right)$

\section{Gênero}

$\mathrm{L}(\mu \mathrm{m})$

$\mathrm{W}(\mu \mathrm{m})$

$\mathrm{D}\left(\mathrm{mm}^{-2}\right)$

$\mathrm{S}\left(\mu \mathrm{m}^{2}\right)$

$\mathrm{a}_{\max }\left(\mu \mathrm{m}^{2}\right)$

$\mathrm{g}_{\mathrm{wmax}}\left(\mathrm{mol} \cdot \mathrm{m}^{-2} \cdot \mathrm{s}^{-1}\right)$

SPI

SLA $\left(\mathrm{cm}^{2} \mathrm{~g}^{-1}\right)$

$\mathrm{N}\left(\mu \mathrm{g} \cdot \mathrm{mm}^{-2}\right)$

$\mathrm{C}\left(\mu \mathrm{g} . \mathrm{mm}^{-2}\right)$

\section{Grupo Funcional x Gênero}

$\begin{array}{ll}19.717 & <0.0001 * * * \\ 23.869 & <0.0001 * * * \\ 0.1564 & 0.6944 \\ 18.966 & <0.0001 * * * \\ 18.966 & <0.0001 * * * \\ 5.5337 & 0.0229 * \\ 13.037 & 0.0008 * * * \\ 16.088 & 0.0002 * * * \\ 0.0196 & 0.8894 \\ 1.5296 & 0.2224\end{array}$

4.438

3.5718

4.0851

3.7723

3.7723

8.4948

10.367

3.301

52.013

36.55
$0.001 * * *$

$0.0044 * *$

$0.0018 * *$

$0.0031 * *$

$0.0031 * *$

$<0.0001 * * *$

$<0.0001 * * *$

$0.0073 * *$

$<0.0001 * * *$

$<0.0001 * * *$

$\mathrm{L}(\mu \mathrm{m})$
$\mathrm{W}(\mu \mathrm{m})$
$\mathrm{D}\left(\mathrm{mm}^{-2}\right)$
$\mathrm{S}\left(\mu \mathrm{m}^{2}\right)$
$\mathrm{a}_{\max }\left(\mu \mathrm{m}^{2}\right)$
$\mathrm{g}_{\mathrm{wmax}}\left(\mathrm{mol} \cdot \mathrm{m}^{-2} \cdot \mathrm{s}^{-1}\right)$
SPI
SLA $\left(\mathrm{cm}^{2} \mathrm{~g}^{-1}\right)$
$\mathrm{N}\left(\mu \mathrm{g} \cdot \mathrm{mm}^{-2}\right)$
$\mathrm{C}\left(\mu \mathrm{g} \cdot \mathrm{mm}^{-2}\right)$

$\begin{array}{ll}38.124 & <0.0001 * * * \\ 18.542 & <0.0001 * * * \\ 51.0034 & <0.0001 * * * \\ 30.937 & <0.0001 * * * \\ 30.937 & <0.0001 * * * \\ 22.214 & <0.0001 * * * \\ 5.2531 & 0.0004 * * * \\ 9.1357 & <0.0001 * * * \\ 8.1309 & <0.0001 * * * \\ 2.6522 & 0.0278 *\end{array}$


A condutância estomática máxima de vapor d'água $\left(\mathrm{g}_{\mathrm{wmax}}\right)$, por sua vez, aparentemente acompanhou o resultado do índice de área do poro estomático (SPI) e da densidade estomática. Sempre que SPI foi maior para uma espécie do par congenérico, a $\mathrm{g}_{\mathrm{wmax}}$ da mesma foi maior, e sempre que SPI foi similar entre as espécies de um par, quem apresentou o maior valor de $g_{w m a x}$ foi a espécie com maior densidade estomática (Tabela 5 e ANEXO).

As duas situações relatadas em que espécies de mata apresentaram densidades estomáticas maiores - o que lhes rendeu índices de área do poro estomático similares às congêneres de cerrado - foram também as únicas em que $\mathrm{g}_{\mathrm{wmax}}$ foi maior para espécies de mata (Guapira e Hymenaea). O gênero Guapira chamou atenção nesse aspecto, uma vez que a espécie de cerrado (G. noxia) apresentou, em média, estômatos 4 vezes maiores, enquanto a espécie de mata (G. gracilifora) apresentou densidade estomática 3 vezes superior, sendo que ambas não diferiram significativamente no índice de área do poro estomático e a espécie de mata apresentou maior $g_{w \max }$. Isso sugere uma relação positiva forte entre densidade estomática e $g_{w m a x}$, bem como entre SPI e $g_{w m a x}$. Adicionalmente, e contrariando as expectativas, $g_{w m a x}$ foi similar entre espécies típicas de cerrado e de mata para três pares congenéricos: Pouteria ramiflora e P. torta, Tabebuia chrysotricha e T. impetiginosa, Vochysia thyrsoidea e V. tucanorum.

Os testes pareados para verificação de diferenças nos conteúdos de nitrogênio e carbono por área foliar só retornaram resultados significativos para Vochysia (maior conteúdo de $\mathrm{N}$ na espécie de mata, $V$. tucanorum) e Xylopia (maior conteúdo de carbono na espécie de cerrado, $X$. aromatica). 
Tabela 5. Resumo dos resultados apontados pelos testes t pareados para tamanho estomático (S), densidade estomática (D), índice de área do poro estomático (SPI) e condutância estomática máxima teórica $\left(\mathrm{g}_{\mathrm{wmax}}\right)$. Resultados indicados por "Maior" e "Menor" indicam diferença estatisticamente significativa, para cada parâmetro $(P<0.05)$, entre as espécies de cerrado comparadas às de mata de cada par congenérico. Os resultados condizentes com as hipóteses do trabalho foram destacados em verde, e os diferentes do esperado em vermelho.

\begin{tabular}{|c|c|c|c|c|c|}
\hline Gênero & Grupo & $\mathbf{S}$ & D & SPI & $g_{w \max }$ \\
\hline $\begin{array}{l}\text { Byrsonima verbascifolia } \\
\text { Byrsonima laxiflora }\end{array}$ & $\begin{array}{l}\text { CERRADO } \\
\text { MATA }\end{array}$ & MAIOR & SIMILAR & MAIOR & MAIOR \\
\hline $\begin{array}{l}\text { Guapira noxia } \\
\text { Guapira graciliflora }\end{array}$ & $\begin{array}{l}\text { CERRADO } \\
\text { MATA }\end{array}$ & MAIOR & Menor & Similar & Menor \\
\hline $\begin{array}{l}\text { Hymenaea stigonocarpa } \\
\text { Hymenaea courbaril }\end{array}$ & $\begin{array}{l}\text { CERRADO } \\
\text { MATA }\end{array}$ & MAIOR & Menor & Similar & Menor \\
\hline $\begin{array}{l}\text { Pouteria ramiflora } \\
\text { Pouteria torta }\end{array}$ & $\begin{array}{l}\text { CERRADO } \\
\text { MATA }\end{array}$ & MAIOR & SIMILAR & Similar & Similar \\
\hline $\begin{array}{l}\text { Qualea parviflora } \\
\text { Qualea dichotoma }\end{array}$ & $\begin{array}{l}\text { CERRADO } \\
\text { MATA }\end{array}$ & Similar & Maior & MAIOR & MAIOR \\
\hline $\begin{array}{l}\text { Tabebuia chrysotricha } \\
\text { Tabebuia impetiginosa }\end{array}$ & $\begin{array}{l}\text { CERRADO } \\
\text { MATA }\end{array}$ & Similar & SIMILAR & Similar & Similar \\
\hline $\begin{array}{l}\text { Vochysia thyrsoidea } \\
\text { Vochysia tucanorum }\end{array}$ & $\begin{array}{l}\text { CERRADO } \\
\text { MATA }\end{array}$ & Similar & SIMILAR & Similar & Similar \\
\hline $\begin{array}{l}\text { Xylopia aromatica } \\
\text { Xylopia brasiliensis }\end{array}$ & $\begin{array}{l}\text { CERRADO } \\
\text { MATA }\end{array}$ & MAIOR & Maior & MAIOR & MAIOR \\
\hline
\end{tabular}


ANÁlises DE EIXO PRINCIPAL PADRONIZADO (SMATRs) - A densidade estomática e o índice de área do poro estomático (SPI) correlacionaram-se forte e positivamente com a condutância estomática máxima de vapor d'água ( $\left.\mathrm{g}_{\mathrm{wmax}}\right)$ (Figuras 8-9). Para a relação entre a densidade estomática e o conteúdo de nitrogênio por área foliar, as SMAs não retornaram valores significativos em termos de grupo funcional $\left(\mathrm{R}^{2}=0.003, P=\right.$ 0.90 para espécies de cerrado, $\mathrm{R}^{2}=0.17, P=0.36$ para espécies mata) e para as espécies tomadas em conjunto $\left(\mathrm{R}^{2}=0.04, P=0.51\right)$ (Figura $\left.10 \mathrm{~A}-\mathrm{B}\right)$. Isto faz sentido uma vez que, considerando o fator gênero, o conteúdo de nitrogênio pouco variou entre as espécies de cada par e a densidade foi, como visto, similar para metade dos pares congenéricos estudados, enquanto em termos de grupos funcionais as médias foram similares para ambas as variáveis.

Já o tamanho estomático (S) correlacionou-se negativamente com o conteúdo de nitrogênio por área foliar para as espécies de cerrado $\left(\mathrm{R}^{2}=0.87, P=0.002\right)$. Para as espécies de mata, este padrão não ocorreu $\left(\mathrm{R}^{2}=0.002, P=0.92\right)$, tampouco para as espécies tomadas em conjunto $\left(\mathrm{R}^{2}=0.11, P=0.23\right)$ (Figura $\left.10 \mathrm{C}-\mathrm{D}\right)$. Além disso, não encontramos correlação significativa entre a condutância estomática máxima de vapor d'água $\left(g_{w m a x}\right)$ e a concentração de nitrogênio por área foliar (Figura 11).

Para espécies de cerrado, $\mathrm{D}$ tende a diminuir com aumento de $\mathrm{S}\left(\mathrm{R}^{2}=0.51, P=0.04\right)$, enquanto para espécies de mata não ocorreu esse padrão $\left(\mathrm{R}^{2}=0.07, P=0.53\right)$, tampouco para as espécies tomadas em conjunto $\left(\mathrm{R}^{2}=0.09, P=0.25\right)$ (Figura 12).

Por fim, encontramos correlação positiva significativa entre a área foliar específica e a concentração de nitrogênio por área foliar para as espécies de cerrado $\left(\mathrm{R}^{2}=0.59, P=0.04\right)$ e para as espécies tomadas em conjunto $\left(\mathrm{R}^{2}=0.43, P=0.01\right)$ (Figura $\left.13 \mathrm{~A}-\mathrm{B}\right)$. 


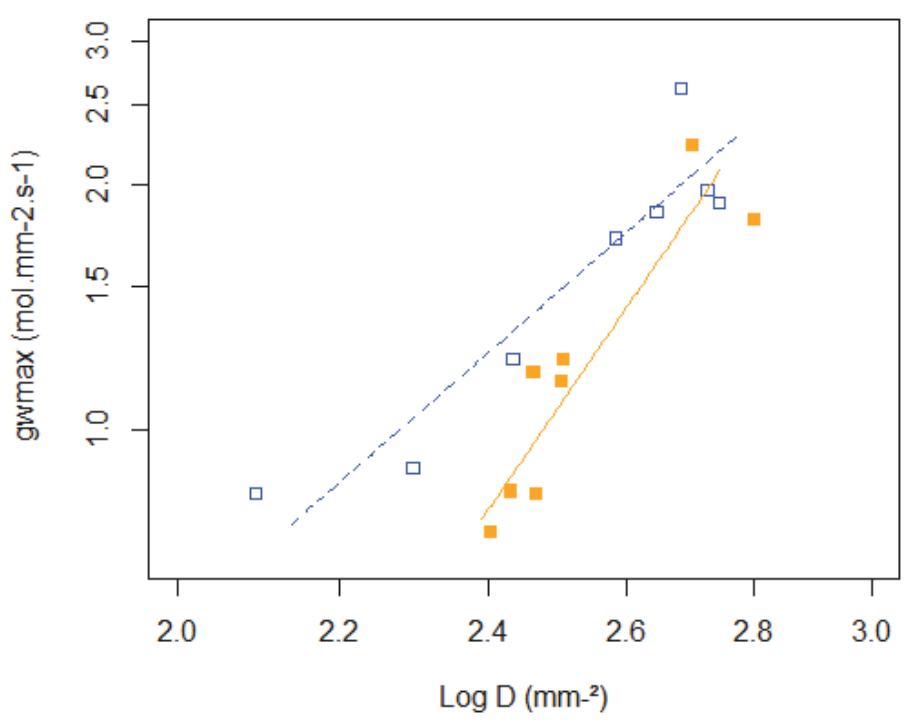

Figura 8. Relação entre densidade estomática (D) e condutância estomática máxima de vapor d'água, $\mathrm{g}_{\mathrm{wmax}}$. Cada ponto corresponde a uma espécie. Espécies de cerrado em azul $\left(\mathbf{R}^{2}=\mathbf{0 . 8 7}, \boldsymbol{P}<\mathbf{0 . 0 0 0 1}\right.$ e de mata em laranja $\left(\mathbf{R}^{2}=\mathbf{0 . 8 1}, \boldsymbol{P}=\mathbf{0 . 0 0 2}\right)$. A comparação entre as linhas alométricas dos grupos não apontou diferenças significativas entre inclinações (slopes) das retas (likelihood ratio statistic $=3.022, \mathrm{df}=1, P=$ $0.08)$.
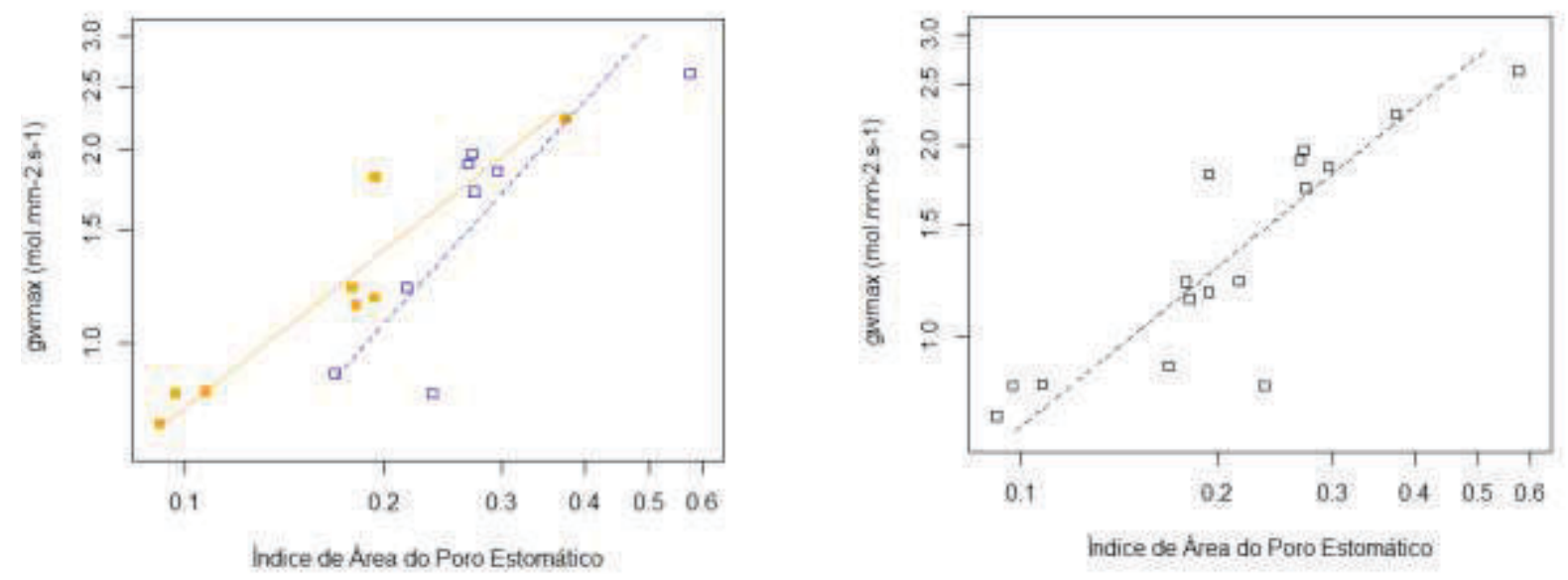

Figura 9. Relação entre o índice de área do poro estomático, SPI, e condutância estomática máxima de vapor d'água, $g_{\text {wmax }}$. Cada ponto corresponde a uma espécie. Espécies de cerrado em azul $\left(\mathbf{R}^{2}=\mathbf{0 . 6 5}, \boldsymbol{P}=\mathbf{0 . 0 1}\right)$ e de mata em laranja $\left(\mathbf{R}^{2}=\mathbf{0 . 8 8}, \boldsymbol{P}=\mathbf{0 . 0 0 1}\right)$. Á direita, espécies tomadas em conjunto $\left(\mathbf{R}^{2}=\mathbf{0 . 7 5}, \boldsymbol{P}<\mathbf{0 . 0 0 0 1}\right)$. A comparação entre as linhas alométricas dos grupos não apontou diferenças significativas entre inclinações (slopes) das retas (likelihood ratio statistic $=1.257, \mathrm{df}=1, P=0.26$ ). 
A

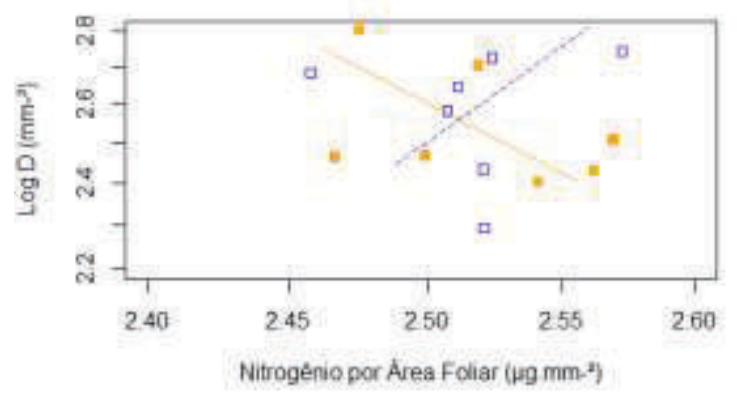

C

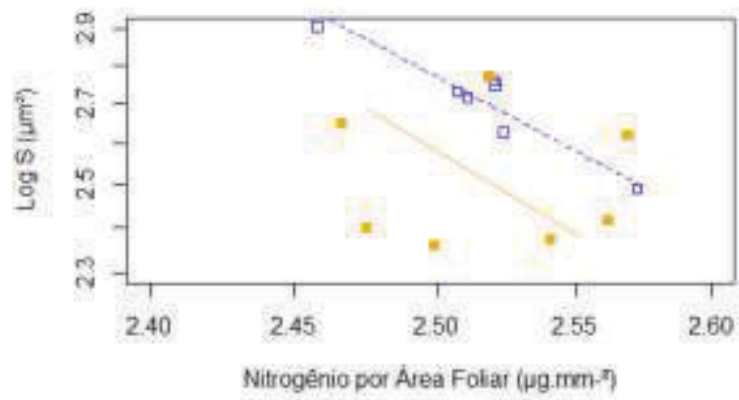

B

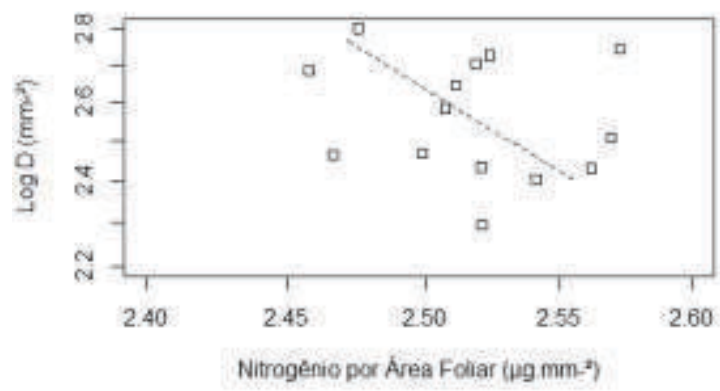

D

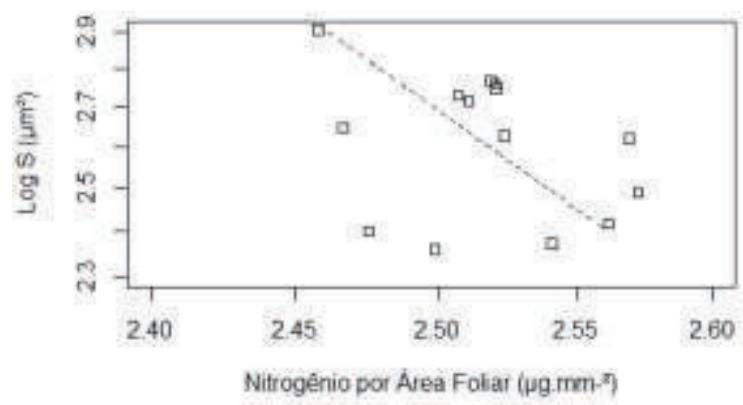

Figura 10. (A) Relação entre densidade estomática, "D", e a concentração de nitrogênio por área foliar, por grupos funcionais $\left(\mathrm{R}^{2}=0.003, P=0.90\right.$ para espécies de cerrado e $\mathrm{R}^{2}=0.17, P=0.36$ para mata) e (B) para as espécies tomadas em conjunto $\left(\mathrm{R}^{2}=0.04, P=0.51\right)$. A comparação entre as linhas alométricas dos grupos não apontou diferenças significativas entre inclinações (slopes) das retas (likelihood ratio statistic $=0.1923, \mathrm{df}=1, P=$ 0.66). (C) Relação entre o tamanho estomático, "S", e concentração de nitrogênio por área foliar, por grupos funcionais $\left(\mathbf{R}^{\mathbf{2}}=\mathbf{0 . 8 7}, \boldsymbol{P}=\mathbf{0 . 0 0 2}\right.$ para espécies de cerrado e $\mathrm{R}^{2}=0.001, P=0.96$ para espécies de mata) e (D) para o conjunto de espécies $\left(\mathrm{R}^{2}=0.10, P=0.26\right)$. A comparação entre as linhas alométricas dos grupos não apontou diferenças significativas entre inclinações (slopes) das retas (likelihood ratio statistic $=0.05245, \mathrm{df}=1, P$ $=0.82$ ). Espécies de cerrado em azul e de mata em laranja. Cada ponto corresponde a uma espécie, sendo que as espécies Guapira noxia e G. gracilifora foram excluídas da análise em razão de apresentarem concentrações médias deste elemento por área foliar muito díspares em relação ao conjunto de dados (outliers). 

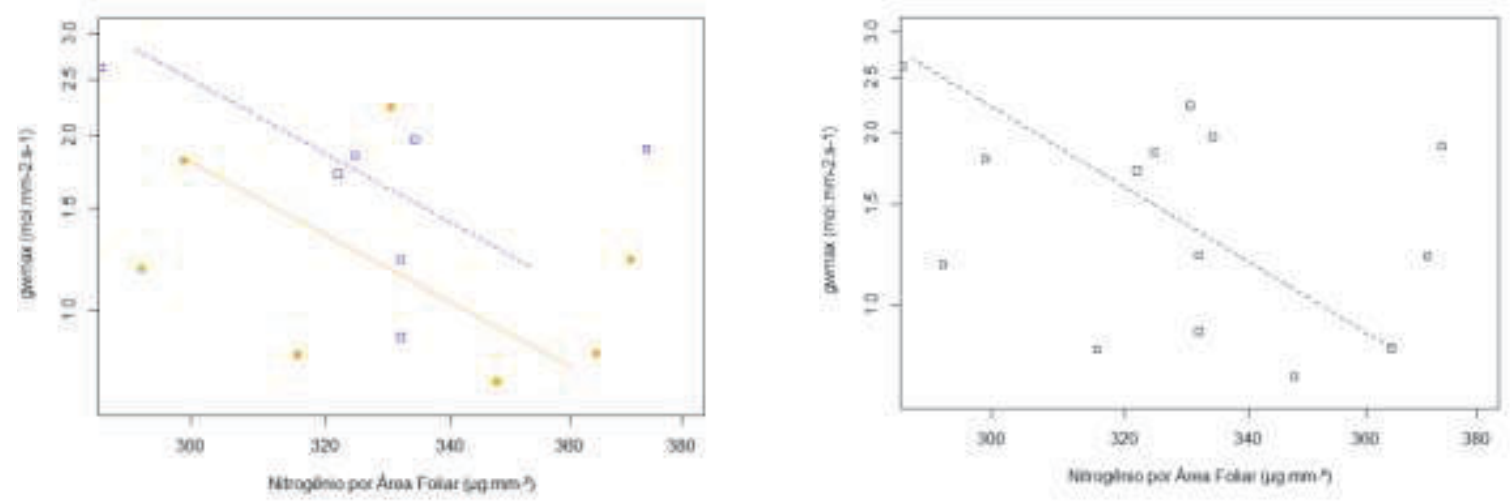

Figura 11. Relação entre condutância estomática máxima de vapor d'água $\left(\mathrm{g}_{\mathrm{wmax}}\right)$ e concentração foliar de nitrogênio em base de área por grupos funcionais $\left(\mathrm{R}^{2}=0.10, P=0.48\right.$ para espécies de cerrado e $\mathrm{R}^{2}=0.12, P$ $=0.45$ para mata) e para as espécies tomadas em conjunto $\left(\mathrm{R}^{2}=0.10, \mathrm{p}=0.27\right)$. Cada ponto corresponde a uma espécie, sendo que as espécies Guapira noxia e G. gracilifora foram excluídas da análise em razão de apresentarem concentrações médias deste elemento por área foliar muito díspares em relação ao conjunto de dados (outliers). A comparação entre as linhas alométricas dos grupos não apontou diferenças significativas entre inclinações (slopes) das retas (likelihood ratio statistic $=0.0054, \mathrm{df}=1, \mathrm{p}=0.94$ ). Espécies de cerrado em azul e de mata em laranja.
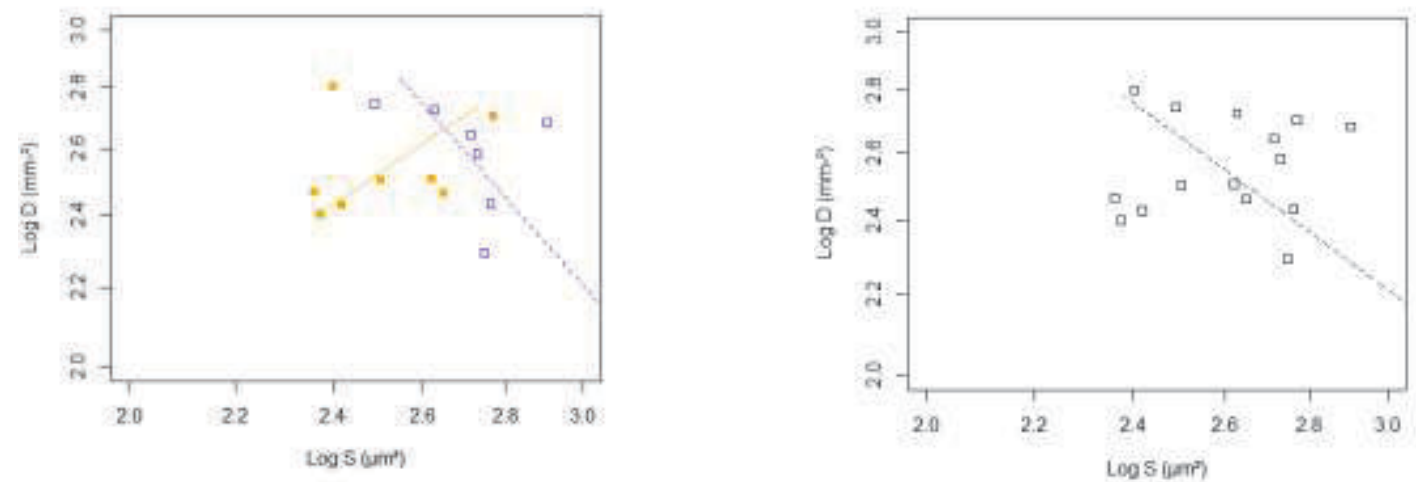

Figura 12. Relação entre densidade (D) e tamanho (S) dos estômatos, para espécies de cerrado $\left(\mathbf{R}^{2}=\mathbf{0 . 5 1}, \boldsymbol{P}=\right.$ 0.04) e mata $\left(\mathrm{R}^{2}=0.07, P=0.53\right)$ à esquerda e para as o conjunto de espécies à direita $\left(\mathrm{R}^{2}=0.09, P=0.25\right)$.

Cada ponto corresponde a uma espécie. A comparação entre as linhas alométricas dos grupos não apontou diferenças significativas entre inclinações (slopes) das retas (likelihood ratio statistic $=0.4732, \mathrm{df}=1, P=0.49$ ). Espécies de cerrado em azul e de mata em laranja. 
A

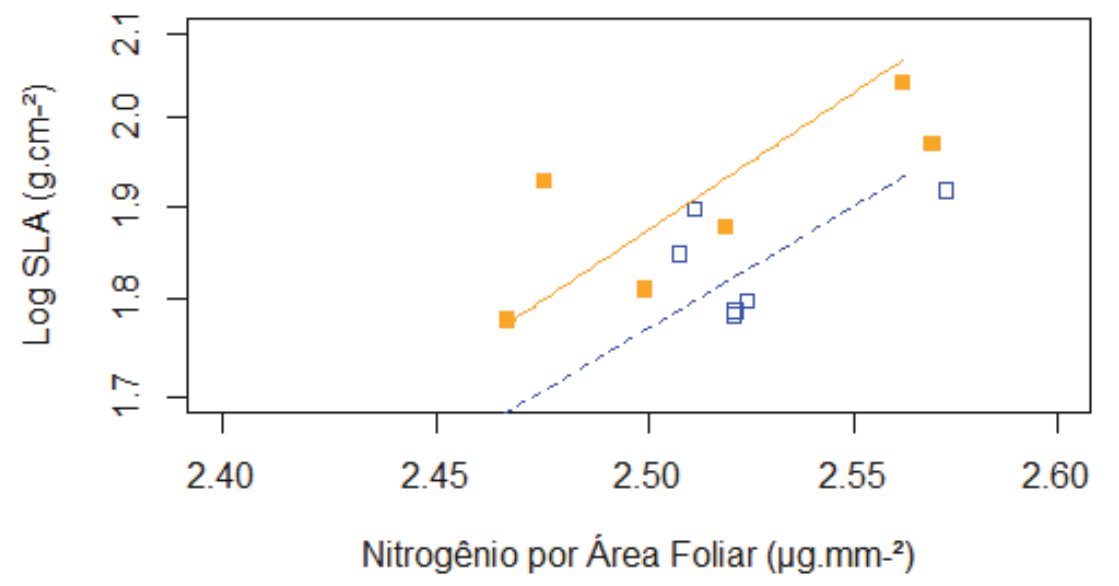

B

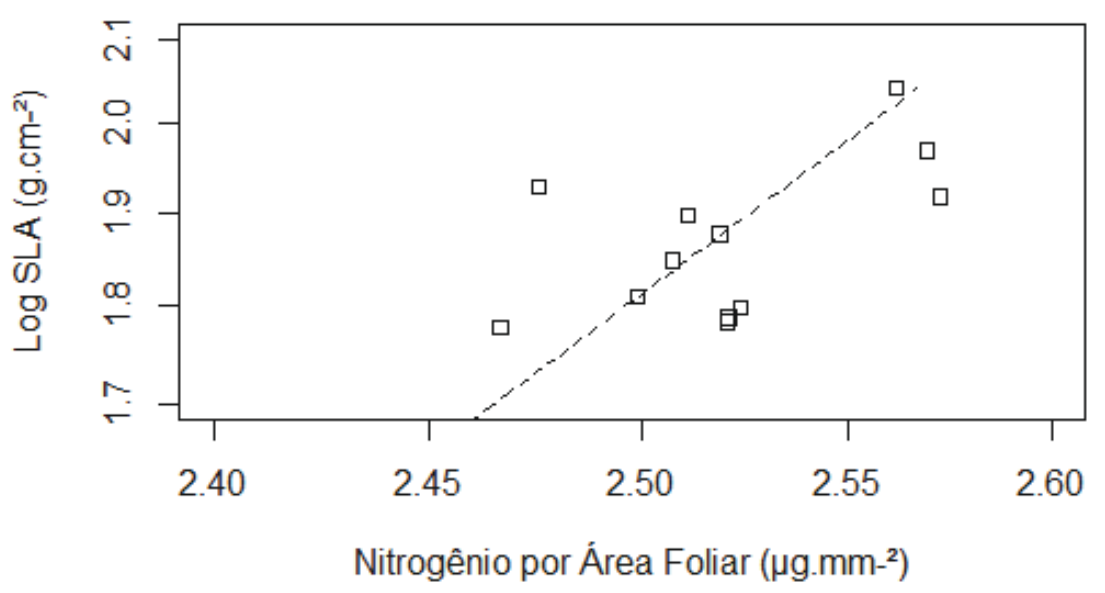

Figura 13. Relação entre área foliar específica (SLA) e concentração nitrogênio por área foliar para (A) espécies de cerrado $\left(\mathbf{R}^{2}=\mathbf{0 . 6 3}, \boldsymbol{P}=\mathbf{0 . 0 3}\right)$ e de mata $\left(\mathrm{R}^{2}=0.50, P=0.07\right)$ e $(\mathbf{B})$ para o conjunto de espécies $\left(\mathbf{R}^{2}\right.$ $=\mathbf{0 . 4 3}, \boldsymbol{P}=\mathbf{0 . 0 1}$ ). Espécies de cerrado em azul e de mata em laranja. Cada ponto corresponde a uma espécie, sendo que as espécies Guapira noxia e G. gracilifora foram excluídas da análise em razão de apresentarem concentrações médias deste elemento por área foliar muito díspares em relação ao conjunto de dados (outliers). A comparação entre as linhas alométricas dos grupos não apontou diferenças significativas entre inclinações (slopes) das retas (likelihood ratio statistic $=0.07103, \mathrm{df}=1, P=0.79$ ). 


\section{DISCUSSÃO}

Constatamos, em termos de médias por grupos funcionais, que as espécies de cerrado estudadas apresentam estômatos maiores e densidades estomáticas estatisticamente similares ao grupo de mata, confirmando os padrões encontrados por Rossatto et al. (2009b). Desse padrão resulta, aparentemente, uma maior alocação de área epidérmica foliar para estômatos em espécies de cerrado (uma vez que apresentam, em média, maiores índices de área do poro estomático), bem como maiores condutâncias máximas de vapor d'água calculadas $\left(\mathrm{g}_{\mathrm{wmax}}\right)$ ou, como o parâmetro vem sendo chamado, maior $\mathrm{g}_{\text {smax }}$ anatômico, o qual pode ser calculado tanto em termos de vapor d'água como de dióxido de carbono (Dow et al. 2014).

Entretanto, os resultados obtidos para os pares congenéricos indicam que a abordagem de médias por grupo funcional (neste caso, por grupos compostos por espécies típicas de cerrado e de mata amostradas numa mesma área transicional entre tais fitofisionomias), pode não ser apropriada se usada isoladamente, uma vez que dentre os oito pares congenéricos estudados, cinco apresentaram valores estatisticamente similares da medida parcial de alocação epidérmica para estômatos (Guapira, Hymenaea, Pouteria, Tabebuia e Vochysia), três apresentaram $\mathrm{g}_{\mathrm{wmax}}$ similares (Pouteria, Tabebuia e Vochysia), dois apresentaram maior $\mathrm{g}_{\mathrm{wmax}}$ para espécies de mata (Guapira e Hymenaea) e apenas três apresentaram maior $\mathrm{g}_{\mathrm{wmax}}$ para espécies de cerrado (Byrsonima, Qualea e Xylopia).

Em nenhuma situação, o tamanho dos estômatos (S) e o índice de área do poro estomático (SPI) foram superiores para as espécies de mata, mas sempre que os valores de SPI foram similares dentro dos pares, independentemente de haver diferenças em S (quando ocorreram, os valores foram maiores para o cerrado), a espécie com maior densidade estomática apresentou valores de $\mathrm{g}_{\mathrm{wmax}}$ maiores. Supomos, deste modo, que para um valor 
fixo de SPI e uma combinação variável de densidades e tamanhos estomáticos, a densidade deverá exercer um peso maior sobre a determinação de $g_{w \max }$ do que o comprimento da célula-guarda.

Conforme observado por Rossatto et al. (2009b), “As características estomáticas tendem a ser mais similares entre espécies de uma mesma família do que entre espécies de familias distintas crescendo num mesmo ambiente. Desta maneira, a variação entre as espécies dos dois ambientes [cerrado e mata de galeria] nos valores de condutância estomática [operacional] parece ser um produto da história evolutiva de cada taxa e não o resultado de uma especialização ao ambiente de cerrado ou de mata de galeria". Em nosso trabalho, os dois pares congenéricos pertencentes à família Vochysiaceae (gêneros Vochysia e Qualea) ilustram bem a observação dos referidos autores. No par Vochysia thyrsoidea (cerrado) e $V$. tucanorum (mata), as espécies não diferiram significativamente em termos de índice de área do poro estomático (SPI) e $g_{\mathrm{wmax}}$, mas apresentaram valores para estas variáveis muito superiores em relação ao conjunto total de espécies. Por outro lado, Qualea parviflora (cerrado) apresentou valores de SPI e $g_{w m a x}$ significativamente maiores em relação a $Q$. dichotoma (mata).

O fato de termos encontrado resultados tão diferentes para dois pares congenéricos pertencentes ao mesmo táxon reforça a ideia de que a alocação de epiderme foliar para estômatos e a condutância estomática máxima são mais influenciadas pelo componente filogenético (em nível de gênero e de espécie) do que propriamente o resultado de convergência evolutiva e diferenciação de estratégias adaptativas de múltiplos táxons às condições específicas de cerrado ou mata. 
O trabalho de Rossatto et al. (2009b), no qual os autores avaliaram características estomáticas para dez pares congenéricos na mesma região, contém cinco gêneros em comum com o presente estudo (Byrsonima, Guapira, Hymenaea, Tabebuia e Vochysia) e apresenta dados de condutâncias estomáticas medidas em campo durante a estação chuvosa de 2006. Isto permitiu-nos comparar, ainda que superficialmente, os valores encontrados para a condutância operacional $\left(\mathrm{g}_{\mathrm{s}}\right)$ e a condutância teórica $\left(\mathrm{g}_{\mathrm{wmax}}\right)$ para cinco gêneros, além de estimar os valores condutância teórica para as espécies estudadas por Rossatto et al. (2009b), aos quais nos referimos como " $\mathrm{g}_{\mathrm{wmax}}$ lit" (Tabela 6).

Tabela 6. Comparação entre condutâncias operacionais $\left(g_{s}\right)$ e teóricas $\left(g_{w m a x}\right)$ para os gêneros em comum entre este trabalho e Rossatto et al. (2009b), sendo " $\mathrm{g}_{\mathrm{wmax}}$ lit" a condutância teórica calculada com base neste último. Diferenças estatisticamente significativas entre espécies de mata e de cerrado, em cada um dos trabalhos, encontram-se destacadas em negrito.

\begin{tabular}{lcccccc}
\hline & \multicolumn{3}{c}{ Cerrado } & & & \multicolumn{3}{c}{ Mata } \\
\hline & $\mathbf{g}_{\mathbf{s}}$ & $\mathbf{g}_{\mathbf{w m a x}}$ lit & $\mathbf{g}_{\text {wmax }}$ & $\mathbf{g}_{\mathbf{s}}$ & $\mathbf{g}_{\text {wmax }}$ lit & $\mathbf{g}_{\text {wmax }}$ \\
\hline Byrsonima & $\mathbf{0 . 0 9 7}$ & 1.27 & $\mathbf{1 . 7 2 0}$ & $\mathbf{0 . 2 0}$ & 1.46 & $\mathbf{0 . 8 4}$ \\
Guapira & $\mathbf{0 . 0 6 8}$ & 0.93 & $\mathbf{0 . 8 4}$ & $\mathbf{0 . 1 6 4}$ & 0.64 & $\mathbf{1 . 1 5}$ \\
Hymenaea & 0.165 & 1.57 & $\mathbf{1 . 2 2}$ & 0.098 & 2.28 & $\mathbf{1 . 8 1}$ \\
Tabebuia & $\mathbf{0 . 1 4 0}$ & 1.30 & 1.97 & $\mathbf{0 . 1 0 6}$ & 1.13 & 1.22 \\
Vochysia & 0.107 & 2.28 & 2.62 & 0.203 & 2.13 & 2.23 \\
\hline
\end{tabular}

Verificamos, com isso, que para os gêneros citados acima $\mathrm{g}_{\mathrm{wmax}}$ é sempre bastante superior a $g_{s}$ para espécies de cerrado e de mata. Por outro lado, os valores de condutância teórica de nosso trabalho e os calculados com base na literatura ( $g_{w m a x}$ lit) foram mais próximos entre si, sendo que as espécies de cerrado dos gêneros Guapira, Hymenaea e 
Vochysia, bem como as espécies de mata dos gêneros Byrsonima e Tabebuia, foram as mesmas nos dois trabalhos.

Rossatto et al. (2013) realizaram um estudo sobre variações sazonais em parâmetros morfológicos, fisiológicos e nutricionais foliares medidos com os mesmos pares que Rossatto et al. (2009b). Neste, demonstraram que (i) existe variação significativa na condutância estomática operacional de vapor d'água $\left(\mathrm{g}_{\mathrm{s}}\right)$ das espécies entre as épocas de seca e chuva, sendo os valores de $\mathrm{g}_{\mathrm{s}}$ maiores na época chuvosa; (ii) as médias de condutância estomática operacional de vapor d'água $\left(\mathrm{g}_{\mathrm{s}}\right)$ foram similares entre grupos funcionais (cerrado e mata) durante a estação chuvosa, oscilando na faixa de 0.14 a $0.16 \mathrm{~mol} \cdot \mathrm{m}^{-2} \cdot \mathrm{s}^{-1}$, mas diferiram entre os grupos no final da estação seca (setembro), oscilando em torno de $0.05 \mathrm{~mol} . \mathrm{m}^{-2} \cdot \mathrm{s}^{-1}$ para espécies de mata (agosto e setembro) e, para espécies de cerrado, entre 0.07 e $0.085 \mathrm{~mol} . \mathrm{m}^{-2} . \mathrm{s}^{-}$ ${ }^{1}$ (agosto e setembro, respectivamente); (iii) nos meses finais da estação seca (agosto e setembro) e no final da estação chuvosa (março), as espécies de cerrado apresentaram taxas de assimilação de carbono em base de área significativamente superiores.

Note-se que os valores medidos em campo por Rossatto et al. (2009b, 2013) estão muito abaixo das estimativas teóricas de $\mathrm{g}_{\mathrm{wmax}}$ que calculamos, sendo que as médias que encontramos para espécies de cerrado e de mata foram, respectivamente, $1.63 \mathrm{~mol} \cdot \mathrm{m}^{-2} \cdot \mathrm{s}^{-1} \mathrm{e}$ $1.25 \mathrm{~mol} . \mathrm{m}^{-2} . \mathrm{s}^{-1}$, valores que se assemelham aos encontrados por Franks et al. (2009) para Eucalyptus globulus no sudoeste da Austrália. Nesse último, os autores verificaram padrões de plasticidade do complexo estomático para uma única espécie em resposta a um gradiente ambiental de precipitação e calcularam valores médios para $g_{\text {wmax }}$ de $1.66 \mathrm{~mol} \cdot \mathrm{m}^{-2} \cdot \mathrm{s}^{-1}$ (sítio mais chuvoso) e $1.25 \mathrm{~mol} \cdot \mathrm{m}^{-2} \cdot \mathrm{s}^{-1}$ (sítio menos chuvoso). 
Considerando que não trabalhamos ao longo de um gradiente ambiental, mas com espécies de mata e cerrado crescendo na mesma área de transição e supondo que, em termos adaptativos, as espécies de mata estariam mais sujeitas ao déficit hídrico que suas congêneres de cerrado, não surpreende que as espécies de cerrado tenham apresentado, em média, valores maiores de condutância teórica, muito embora, como vimos, essa relação não seja tão simples quando analisamos os resultados específicos para cada par congenérico.

A verificação das relações entre a condutância estomática teórica, $g_{w m a x}$, e o conteúdo de nitrogênio por área foliar, bem como entre densidade e tamanho dos estômatos, ambas demonstradas por Franks et al. (2009), ficou um pouco prejudicada considerando que trabalhamos com um conjunto de espécies filogeneticamente diversificado e que não houve diferença significativa entre as concentrações de nitrogênio em termos de pares congenéricos ou grupos funcionais, exceto para Vochysia (o único gênero em que, por outro lado, não encontramos diferença significativa para nenhum dos parâmetros estomáticos analisados). Adicionalmente, os autores encontraram essas relações para uma alocação fixa de estômatos por área epidérmica foliar, o que também não se adequa ao presente conjunto de dados. Isso não significa, contudo, que a relação nitrogênio por área foliar $v s . g_{w \max }$ não exista, mas que para melhor investigá-la precisaríamos garantir a inclusão de um número maior de pares e que resultasse em uma maior faixa de variação nos valores de condutância e de nitrogênio para cada espécie.

Dow et al. (2014) realizaram um experimento em que mediram condutâncias estomáticas operacionais $\left(\mathrm{g}_{\mathrm{s}}\right)$ em seis genótipos de Arabidopsis thaliana resultantes de mutações ou de atividade transgênica no desenvolvimento de estômatos, os quais possuem diferentes perfis de $\mathrm{g}_{\mathrm{wmax}}$ anatômico $\left(\mathrm{g}_{\mathrm{wmax}}\right.$ para vapor d'água ou $\mathrm{g}_{\mathrm{cmax}}$ para $\left.\mathrm{CO}_{2}\right)$. Os autores concluíram que $g_{\text {wmax }}$ é um preditor acurado da condutância operacional sob condições de 
trocas gasosas que maximizam a abertura estomática (alta intensidade luminosa, baixa concentração de $\mathrm{CO}_{2}$ e alta umidade relativa), sendo que plantas com diferentes $\mathrm{g}_{\text {smax }}$ anatômicos apresentaram respostas quantitativamente similares ao aumento na concentração de $\mathrm{CO}_{2}$ quando a condutância operacional foi escalada com a estimada teoricamente.

O referido grupo de pesquisa produziu e testou um modelo empírico derivado da equação de Ball-Woodrow-Berry, a qual estima a condutância estomática operacional como uma função de $g_{w \max }$ anatômico, da umidade relativa e concentração de dióxido de carbono na folha, “(...) demonstrando a ligação precisa entre desenvolvimento estomático e a fisiologia foliar e gerando a possibilidade de quantificar acuradamente o fluxo de gases através de folhas sob regimes de concentração atmosférica de dióxido de carbono passados, presentes e futuros".

Os valores médios para $\mathrm{g}_{\text {smax }}$ variaram entre $0.45 \mathrm{~mol} . \mathrm{m}^{-2} . \mathrm{s}^{-1}$ (genótipo que desenvolveu menores valores para densidade e tamanho estomáticos) e $2.13 \mathrm{~mol} . \mathrm{m}^{-2} \cdot \mathrm{s}^{-1}$ (genótipo que desenvolveu maiores valores para densidade e tamanho estomáticos) (Dow et al. 2014). Todavia, testar esse modelo no contexto de pares congenéricos de espécies de cerrado e mata seria um desafio experimental, considerando que no ambiente de cerrado e áreas transicionais cerrado-mata as espécies operam sob forte regulação estomática.

Conforme Franks et al. (2009), apesar de diferentes combinações de tamanho (S) e densidade estomática (D) renderem, em diversas situações, valores similares de condutância teórica, quando $g_{w \max }$ é alterada dentro da zona de plasticidade fenotípica da espécie em resposta a fatores ambientais ou internos (i.e. chuva, disponibilidade de nitrogênio), isso é feito através de uma relação negativa entre $\mathrm{S}$ e $\mathrm{D}$, na qual $\mathrm{S}$ diminui com o aumento de $\mathrm{D}$. A observação é consistente com a relação geral reportada por Franks \& Beerling (2009) ao 
longo de múltiplas espécies e escalas temporais, sugerindo uma interrelação fundamental entre S e D que governa as adaptações em curto prazo (plásticas) e longo prazo (evolutivas) de $g_{\text {wmax }}\left(\right.$ e $\left.g_{\text {cmax }}\right)$ ao ambiente.

Para os autores, uma explicação para essa relação consiste na melhoria da economia de alocação espacial na superfície foliar para estômatos. Considerando uma alocação epidérmica fixa para estômatos, apesar das vantagens potenciais de estômatos menores e mais numerosos (maior $g_{w \max }$ e desempenho dinâmico aprimorado), a relação negativa entre S e D implica um custo associado a números maiores de estômatos menores, e a reversão para estômatos maiores e menos numerosos pode ser uma estratégia melhor para condições em que uma menor $g_{w \max }$ seja suficiente (Franks et al. 2009). Em nosso trabalho, conseguimos verificar esta relação negativa entre $\mathrm{S}$ e D apenas para o conjunto de espécies típicas de cerrado, embora seja necessário salientar, mais uma vez, que a relação não foi analisada em nível de espécie ao longo de um gradiente ambiental.

Apesar de termos encontrado diferenças significativas entre as estimativas de $\mathrm{g}_{\mathrm{wmax}}$ para cinco dos oito pares congenéricos de espécies estudados, não pudemos ter clareza das estratégias evolutivas em termos de grupos funcionalmente diferenciados, uma vez que três gêneros apresentaram maior $\mathrm{g}_{\mathrm{wmax}}$ para espécies de cerrado e dois para espécies de mata. É possível que exista correlação entre $g_{w \max }$ e $g_{s}$, sendo $g_{s}$ função da interação entre o complexo estomático, de características das espécies e fatores ambientais. A análise comparativa de padrões estomáticos das espécies típicas de mata em seu ambiente "original” e em áreas de transição cerrado-mata poderia ajudar na elucidação deste tópico e, adicionalmente, na verificação da relação entre $g_{w \max }$ e o conteúdo de nitrogênio por área foliar ao longo de um gradiente ambiental de disponibilidade hídrica e de nutrientes. 


\section{REFERÊNCIAS BIBLIOGRÁFICAS}

Barros, F. D. V, Goulart, M. F., Telles, S. B. S., Lovato, M. B., Valladares, F., \& de LemosFilho, J. P. (2012). Phenotypic plasticity to light of two congeneric trees from contrasting habitats: Brazilian Atlantic Forest versus cerrado (savanna). Plant Biology (Stuttgart, Germany), 14(1), 208-15. http://doi.org/10.1111/j.1438-8677.2011.00474.x

Berry, J. A., Beerling, D. J., \& Franks, P. J. (2010). Stomata: key players in the earth system, past and present. Current Opinion in Plant Biology, 13(3), 232-239.

Caldas, L. S., Bravo, C., Piccolo, H., Faria, C. R. S. M., Botânica, D. De, Biológicas, I. D. C., \& Brasilia, U. De. (1992). Measurement of leaf area with a hand-scanner linked to a microcomputer. Revista Brasileira de Fisiologia Vegetal 1, 4(1), 17-20.

Capuzzo, J. P., Rossatto, D. R., \& Franco, A. C. (2012). Differences in morphological and physiological leaf characteristics between Tabebuia aurea and $T$. impetiginosa is related to their typical habitats of occurrence. Acta Botanica Brasilica 26(3), 519-526.

Coley, P. D., Bryant, J. P., \& Chapin, F. S. (1985). Resource availability and plant antiherbivore defense. Science, 230(4728), 895-899.

Cramer, W., Bondeau, A., Woodward, F. I., Prentice, I. C., Betts, R. A., Brovkin, V., ... \& Kucharik, C. (2001). Global response of terrestrial ecosystem structure and function to $\mathrm{CO} 2$ and climate change: results from six dynamic global vegetation models. Global change biology, 7(4), 357-373.

Cutler, D. F., Botha, T., \& Stevenson, D. W. (2009). Anatomia Vegetal: uma abordagem aplicada. Artmed Editora. 
Davies, T. J., Barraclough, T. G., Chase, M. W., Soltis, P. S., Soltis, D. E., \& Savolainen, V. (2004). Darwin's abominable mystery: Insights from a supertree of the angiosperms. PNAS 101(7), 1904-1911.http://www.pnas.org_cgi_doi_10.1073_pnas.0308127100

Dow, G. J., Bergmann, D. C., \& Berry, J. A. (2014). An integrated model of stomatal development and leaf physiology. New Phytologist, 201(4), 1218-1226.

Felsenstein, J. (1985). Phylogenies and the comparative method. American Naturalist 125, 115.

Franco, A. C. \& Haridasan, M. (2008). Cerrado. In Encyclopedia of Life Support Systems (EOLSS). Eolss Publishers, Oxford, UK. Retrieved from http://www.eolss.net/samplechapters/c20/e6-142-tb-15.pdf

Franco, A. C., Rossatto, D. R., Silva, L. D. C. R., \& da Silva Ferreira, C. (2014). Cerrado vegetation and global change: the role of functional types, resource availability and disturbance in regulating plant community responses to rising $\mathrm{CO} 2$ levels and climate warming. Theoretical and Experimental Plant Physiology, 26(1), 19-38.

Franks, P. J., \& Beerling, D. J. (2009). Maximum leaf conductance driven by CO2 effects on stomatal size and density over geologic time. PNAS 106(25), 10343-10347.

Franks, P. J., Drake, P. L., \& Beerling, D. J. (2009). Plasticity in maximum stomatal conductance constrained by negative correlation between stomatal size and density: an analysis using Eucalyptus globulus. Plant, Cell \& Environment 32, 1737-1748. http://doi.org/10.1111/j.1365-3040.2009.002031.x 
Franks, P. J., Leitch, I. J., Ruszala, E. M., Hetherington, A. M., \& Beerling, D. J. (2012). Physiological framework for adaptation of stomata to CO 2 from glacial to future concentrations. Phil. Trans. R. Soc. B 367, 537-546. doi:10.1098/rstb.2011.0270

Hetherington, A. M., \& Woodward, F. I. (2003). The role of stomata in sensing and driving environmental change. Nature, 424(6951), 901-908.

Hoffmann, W. a, Geiger, E. L., Gotsch, S. G., Rossatto, D. R., Silva, L. C. R., Lau, O. L., ... Franco, A. C. (2012). Ecological thresholds at the savanna-forest boundary: how plant traits, resources and fire govern the distribution of tropical biomes. Ecology Letters, 15(7), 759-68. http://doi.org/10.1111/j.1461-0248.2012.01789.x

Hoffmann, W. a., Franco, a. C., Moreira, M. Z., \& Haridasan, M. (2005). Specific leaf area explains differences in leaf traits between congeneric savanna and forest trees. Functional Ecology, 19(6), 932-940. http://doi.org/10.1111/j.1365-2435.2005.01045.x

Jackson, R. B., Carpenter, S. R., Dahm, C. N., McKnight, D. M., Naiman, R. J., Postel, S. L., \& Running, S. W. (2001). Water in a changing world. Ecological applications, 11(4), 1027-1045.

Johansen, Donald Alexander (1940). "Plant microtechnique." Plant microtechnique.

Kuhlmann, M. (2012). Frutos e sementes do Cerrado atrativos para fauna: guia de campo. Brasília: Rede de Sementes do Cerrado.

Lambers, H., Chapin, F. S., \& III\&, P. TL.(1998) Plant Physiological Ecology. 
Metcalfe, C. R., \& Chalk, L. (1979). Anatomy of the dicotyledons. v.1: Systematic anatomy of leaf and stem; with a brief history of the subject. $2^{\text {nd }}$ ed. Oxford: Claredon Press. $276 \mathrm{p}$.

Pereira, B. A. S., Silva, M. A., \& Mendonça, R. C. (2004). Reserva ecológica do IBGE: ambiente e plantas vasculares. Rio de Janeiro, IBGE. Coordenação de Recursos Naturais e Estudos Ambientais.

Poorter, L., \& Bongers, F. (2006). Leaf traits are good predictors of plant performance across 53 rain forest species. Ecology, 87(7), 1733-1743.

R Development Core Team (2012). RStudio: integrated development environment for R. Massachusetts.

Reich, P. (1997). From tropics to tundra: global convergence in plant functioning. PNAS 94, 13730-13734. Retrieved from http://www.pnas.org/content/94/25/13730.short

Rossatto, D. R., Hoffmann, W. A., \& Franco, A. C. (2009a). Differences in growth patterns between co-occurring forest and savanna trees affect the forest-savanna boundary. Functional Ecology, 23(4), 689-698.

Rossatto, D. R., Hoffmann, W. A., \& Franco, A. C. (2009b). Características estomáticas de pares congenéricos de cerrado e mata de galeria crescendo numa região transicional no Brasil Central. Acta Botanica Brasilica 23(2): 499-508.

Rossatto, D. R., Hoffmann, W. A., de Carvalho Ramos Silva, L., Haridasan, M., Sternberg, L. S. L., \& Franco, A. C. (2013). Seasonal variation in leaf traits between congeneric savanna and forest trees in Central Brazil: implications for forest expansion into savanna. Trees, 27(4), 1139-1150. http://doi.org/10.1007/s00468-013-0864-2 
Sano, S. M., de Almeida, S. P., \& Ribeiro, J. F. (2008). Cerrado: ecologia e flora.

Silva-Júnior, M.C., \& Santos, G.C. (2012). 100 Árvores do Cerrado: guia de campo. Rede de Sementes do Cerrado.

Silva-Júnior, M. C., \& Pereira, B. A. S. (2009). + 100 árvores do Cerrado-Matas de Galeria: guia de campo. Brasília, Ed. Rede de Sementes do Cerrado.

Simon, M. F., \& Pennington, T. (2012). Evidence for Adaptation to Fire Regimes in the Tropical Savannas of the Brazilian Cerrado. International Journal of Plant Sciences, 173(6), 711-723. http://doi.org/10.1086/665973

Somavilla, N. S., Kolb, R. M., \& Rossatto, D. R. (2013). Leaf anatomical traits corroborate the leaf economic spectrum: a case study with deciduous forest tree species. Brazilian Journal of Botany, 37(1), 69-82. http://doi.org/10.1007/s40415-013-0038-x

Taiz, L., \& Zeiger E. (2013). Fisiologia vegetal. Porto Alegre: Artmed.

Valladares, F., \& Niinemets, Ü. (2008). Shade Tolerance, a Key Plant Feature of Complex Nature and Consequences. Annual Review of Ecology, Evolution, and Systematics, 39(1), 237-257. http://doi.org/10.1146/annurev.ecolsys.39.110707.173506

Vannucci, L. A., \& Rezende, M. H. (2003). Anatomia Vegetal: noções básicas.

Warton, D. I., Duursma, R. A., Falster, D. S., \& Taskinen, S. (2012). smatr 3-an R package for estimation and inference about allometric lines. Methods in Ecology and Evolution, 3(2), 257-259.

Wright, I. J., Reich, P. B., \& Westoby, M. (2003). Least-Cost Input Mixtures of Water and Nitrogen for Photosynthesis. The American Naturalist 161(1). 
Wright, I.J., Reich, P.B., Westoby M., Ackerly, D.D., Baruch, Z., Bongers, F., CavenderBares, J., Chapin, T., Cornelissen, J.H.C., Diemer, M., ... \& Flexas, J. (2004). The worldwide leaf economics spectrum. Nature 428:821-827. 


\section{ANEXO}

Resultados dos testes t pareados para verificação de diferenças nos parâmetros analisados para cada par congenérico. Resultados significativos encontram-se destacados em negrito $(P<0.05)$.

\begin{tabular}{|c|c|c|c|c|c|c|}
\hline \multirow[t]{2}{*}{ Gêneros } & \multirow[t]{2}{*}{ Parâmetros } & \multicolumn{2}{|c|}{ Média \pm DP } & \multicolumn{3}{|c|}{ Teste t pareado } \\
\hline & & $\mathrm{C}$ & $\mathrm{M}$ & df & $\mathrm{T}$ & $P$ \\
\hline \multirow[t]{10}{*}{ Byrsonima } & $\mathrm{L}(\mu \mathrm{m})$ & $26.37165 \pm 2.142034$ & $18.31552 \pm 0.704412$ & 2 & 5.644 & 0.02999 \\
\hline & $\mathrm{W}(\mu \mathrm{m})$ & $18.73008 \pm 2.397987$ & $12.43461 \pm 1.384466$ & 2 & 2.9945 & 0.09577 \\
\hline & $\mathrm{D}\left(\mathrm{mm}^{-2}\right)$ & $412.3654 \pm 31.03268$ & $293.2856 \pm 74.74677$ & 2 & 2.0922 & 0.1715 \\
\hline & $\mathrm{S}\left(\mu \mathrm{m}^{2}\right)$ & $491.0674 \pm 81.76354$ & $228.8611 \pm 33.3132$ & 2 & 4.3421 & 0.04916 \\
\hline & $a_{\max }\left(m^{2}\right)$ & $5.89 \times 10^{-11} \pm 9.81 \times 10^{-12}$ & $2.75 \times 10^{-11} \pm 3.1 \times 10^{-12}$ & 2 & 4.3421 & 0.04916 \\
\hline & $\mathrm{g}_{\mathrm{wmax}}\left(\mathrm{mol} \cdot \mathrm{m}^{-2} \cdot \mathrm{s}^{-1}\right)$ & $1.718471 \pm 0.1046557$ & $0.8367355 \pm 0.168739$ & 2 & 5.6977 & 0.02945 \\
\hline & SPI & $0.2040486 \pm 0.02304884$ & $0.06512456 \pm 0.007265106$ & 2 & 6.1261 & 0.02563 \\
\hline & $\operatorname{SLA}\left(\mathrm{cm}^{2} \cdot \mathrm{g}^{-1}\right)$ & $70.42776 \pm 6.33683$ & $64.44576 \pm 7.113762$ & 2 & 0.77625 & 0.5188 \\
\hline & $\mathrm{N}\left(\mu \mathrm{g} \cdot \mathrm{mm}^{-2}\right)$ & $1.4046 \pm 0.06097114$ & $1.321167 \pm 0.1034428$ & 2 & 0.9525 & 0.4414 \\
\hline & $\mathrm{C}\left(\mu \mathrm{g} \cdot \mathrm{mm}^{-2}\right)$ & $50.32967 \pm 0.3970445$ & $52.11467 \pm 1.86738$ & 2 & -1.8835 & 0.2003 \\
\hline Guapira & $\mathrm{L}(\mu \mathrm{m})$ & $43.49585 \pm 2.220348$ & $23.83222 \pm 0.5330321$ & 2 & 19.574 & 0.0026 \\
\hline
\end{tabular}




$\begin{array}{lc}\mathrm{W}(\mu \mathrm{m}) & 27.54174 \pm 1.813726 \\ \mathrm{D}\left(\mathrm{mm}^{-2}\right) & 124.1805 \pm 11.90234 \\ \mathrm{~S}\left(\mu \mathrm{m}^{2}\right) & 1201.982 \pm 138.9285 \\ \mathrm{a}_{\max }\left(\mathrm{m}^{2}\right) & 1.44 \times 10^{-10} \pm 1.66 \times 10^{-11} \\ \mathrm{~g}_{\mathrm{wmax}}\left(\mathrm{mol} \cdot \mathrm{m}^{-2} \cdot \mathrm{s}^{-1}\right) & 0.8390758 \pm 0.1264314 \\ \mathrm{SPI} & 0.1494486 \pm 0.03229491 \\ \mathrm{SLA}\left(\mathrm{cm}^{2} \cdot \mathrm{g}^{-1}\right) & 65.8156 \pm 12.74277 \\ \mathrm{~N}\left(\mu \mathrm{g} \cdot \mathrm{mm}^{-2}\right) & 3.769333 \pm 0.08251456 \\ \mathrm{C}\left(\mu \mathrm{g} \cdot \mathrm{mm}^{-2}\right) & 51.74 \pm 1.341521 \\ & \\ \mathrm{~L}(\mu \mathrm{m}) & 28.17574 \pm 0.4817243 \\ \mathrm{~W}(\mu \mathrm{m}) & 20.52425 \pm 1.136526 \\ \mathrm{D}\left(\mathrm{mm}-{ }^{2}\right) & 271.5099 \pm 7.119384 \\ \mathrm{~S}\left(\mu \mathrm{m}^{2}\right) & 578.4489 \pm 38.29338 \\ \mathrm{a}_{\max }\left(\mathrm{m}^{2}\right) & 6.94 \times 10^{-11} \pm 4.59 \times 10^{-12} \\ \mathrm{~g}_{\mathrm{wmax}}\left(\mathrm{mol}^{2} \cdot \mathrm{m}^{-2} \cdot \mathrm{s}^{-1}\right) & 1.223227 \pm 0.05963971 \\ \mathrm{SPI} & 0.1569507 \pm 0.01391375 \\ \mathrm{SLA}\left(\mathrm{cm}^{2} \cdot \mathrm{g}^{-1}\right) & 60.66879 \pm 2.713632 \\ \mathrm{~N}\left(\mu \mathrm{gg} \cdot \mathrm{mm}^{-2}\right) & 1.636367 \pm 0.1503486\end{array}$

$\begin{array}{cccc}13.35675 \pm 0.1420259 & 2 & 13.739 & \mathbf{0 . 0 0 5 2 6} \\ 318.7887 \pm 8.012122 & 2 & -86.017 & \mathbf{0 . 0 0 0 1 4} \\ 318.6091 \pm 8.592001 & 2 & 11.622 & \mathbf{0 . 0 0 7 3 2} \\ 3.82 \times 10^{-11} \pm 1.03 \times 10^{-12} & 2 & 11.622 & \mathbf{0 . 0 0 7 3 2} \\ 1.147468 \pm 0.05143414 & 2 & -7.0805 & \mathbf{0 . 0 1 9 3 7} \\ 0.1013625 \pm 0.005513429 & 2 & 2.8109 & 0.1067 \\ 93.83495 \pm 4.785409 & 2 & -6.082 & \mathbf{0 . 0 2 5 9 8} \\ 3.825433 \pm 0.2686865 & 2 & -0.31407 & 0.7832 \\ 49.417 \pm 1.95064 & 2 & 1.5289 & 0.2659 \\ 17.48536 \pm 1.138259 & 2 & 27.777 & \mathbf{0 . 0 0 1 2 9} \\ 14.29516 \pm 1.168646 & 2 & 8.1056 & \mathbf{0 . 0 1 4 8 8} \\ 632.4767 \pm 23.27745 & 2 & -22.856 & \mathbf{0 . 0 0 1 9 1} \\ 251.5796 \pm 36.72598 & 2 & 16.793 & \mathbf{0 . 0 0 3 5 3} \\ 3.02 \times 10^{-11} \pm 4.41 \times 10^{-12} & 2 & 16.793 & \mathbf{0 . 0 0 3 5 3} \\ 1.805796 \pm 0.1349764 & 2 & -8.9892 & \mathbf{0 . 0 1 2 1 5} \\ 0.1582358 \pm 0.02324296 & 2 & 2.7961 & 0.1076 \\ 84.62295 \pm 9.64355 & 2 & -3.9644 & 0.05813 \\ 1.139603 \pm 0.3213176 & 2 & 1.9515 & 0.1903\end{array}$


$\mathrm{C}\left(\mu \mathrm{g} \cdot \mathrm{mm}^{-2}\right)$

\begin{tabular}{|c|c|c|}
\hline Pouteria & $\mathrm{L}(\mu \mathrm{m})$ & $29.02576 \pm 2.179438$ \\
\hline & $\mathrm{W}(\mu \mathrm{m})$ & $19.25248 \pm 0.7813454$ \\
\hline & $\mathrm{D}\left(\mathrm{mm}^{-2}\right)$ & $197.3547 \pm 26.90139$ \\
\hline & $\mathrm{S}\left(\mu \mathrm{m}^{2}\right)$ & $560.2613 \pm 61.907$ \\
\hline & $\mathrm{a}_{\max }\left(\mathrm{m}^{2}\right)$ & $6.72 \times 10^{-11} \pm 7.43 \times 10^{-12}$ \\
\hline & $\mathrm{g}_{\mathrm{wmax}}\left(\operatorname{mol} \cdot \mathrm{m}^{-2} \cdot \mathrm{s}^{-1}\right)$ & $0.9003098 \pm 0.1759517$ \\
\hline & SPI & $0.110617 \pm 0.02530325$ \\
\hline & $\operatorname{SLA}\left(\mathrm{cm}^{2} \cdot \mathrm{g}^{-1}\right)$ & $61.25352 \pm 1.757586$ \\
\hline & $\mathrm{N}\left(\mu \mathrm{g} \cdot \mathrm{mm}^{-2}\right)$ & $1.6385 \pm 0.08436889$ \\
\hline & $\mathrm{C}\left(\mu \mathrm{g} \cdot \mathrm{mm}^{-2}\right)$ & $54.03533 \pm 0.6563089$ \\
\hline Qualea & $\mathrm{L}(\mu \mathrm{m})$ & $25.85918 \pm 0.8595102$ \\
\hline & $\mathrm{W}(\mu \mathrm{m})$ & $19.99877 \pm 0.9453573$ \\
\hline & $\mathrm{D}\left(\mathrm{mm}-{ }^{2}\right)$ & $442.1844 \pm 30.65084$ \\
\hline & $\mathrm{S}\left(\mu \mathrm{m}^{2}\right)$ & $517.9964 \pm 41.26424$ \\
\hline & $\mathrm{a}_{\max }\left(\mathrm{m}^{2}\right)$ & $6.22 \times 10^{-11} \pm 4.95 \times 10^{-12}$ \\
\hline & $\mathrm{g}_{\mathrm{wmax}}\left(\operatorname{mol} \cdot \mathrm{m}^{-2} \cdot \mathrm{s}^{-1}\right)$ & $1.850265 \pm 0.1537978$ \\
\hline & SPI & $0.2285944 \pm 0.02539715$ \\
\hline
\end{tabular}

$52.90267 \pm 0.8175086$

$2 \quad 0.92133$

0.4541

$19.96454 \pm 0.6082106$

$13.10394 \pm 0.2382232$

$269.3519 \pm 33.04356$

$261.7553 \pm 9.22903$

$3.14 \times 10^{-11} \pm 1.11 \times 10^{-12}$

$0.8423048 \pm 0.09964992$

$0.07056059 \pm 0.007363774$

$109.9353 \pm 21.42567$

$2.140067 \pm 0.1588504$

$52.88433 \pm 1.135976$

$25.85914 \pm 0.7552252$

$17.22108 \pm 0.4924316$

$290.7353 \pm 37.46788$

$445.7542 \pm 22.99677$

$5.35 \times 10^{-11} \pm 2.76 \times 10^{-12}$

$1.17686 \pm 0.1249532$

$0.1287892 \pm 0.01091487$
27.759

219.568

$\begin{array}{ll}2 & -2.2409\end{array}$

$2 \quad 9.2383$

$2 \quad 9.2383$

$2 \quad 0.39133$

21.8815

$2 \quad-4.0886$

$\begin{array}{ll}2 & -3.5919\end{array}$

$2 \quad 1.3931$

2 3.79E-05

23.4046

$2 \quad 5.9453$

$2 \quad 1.9483$

$2 \quad 1.9483$

28.3265

$2 \quad 6.5321$
0.06952

0.2982

0.01621

0.0026

0.1543

0.01151

0.01151

0.7333

0.2006

0.05494

0.0765

0.02714

0.1907

0.1907

0.01412

0.02264 
$\operatorname{SLA}\left(\mathrm{cm}^{2} \cdot \mathrm{g}^{-1}\right)$

$\mathrm{N}\left(\mu \mathrm{g} \cdot \mathrm{mm}^{-2}\right)$

$\mathrm{C}\left(\mu \mathrm{g} \cdot \mathrm{mm}^{-2}\right)$

Tabebuia

$\mathrm{L}(\mu \mathrm{m})$
$\mathrm{W}(\mu \mathrm{m})$
$\mathrm{D}\left(\mathrm{mm}^{-2}\right)$

$\mathrm{S}\left(\mu \mathrm{m}^{2}\right)$

$\mathrm{a}_{\max }\left(\mathrm{m}^{2}\right)$

$\mathrm{g}_{\mathrm{w} \max }\left(\operatorname{mol} \cdot \mathrm{m}^{-2} \cdot \mathrm{s}^{-1}\right)$

SPI

SLA $\left(\mathrm{cm}^{2} \cdot \mathrm{g}^{-1}\right)$

$\mathrm{N}\left(\mu \mathrm{g} \cdot \mathrm{mm}^{-2}\right)$

$\mathrm{C}\left(\mu \mathrm{g} \cdot \mathrm{mm}^{-2}\right)$

Vochysia

$\mathrm{L}(\mu \mathrm{m})$
$\mathrm{W}(\mu \mathrm{m})$
$\mathrm{D}\left(\mathrm{mm}^{2}\right)$
$\mathrm{S}\left(\mu \mathrm{m}^{2}\right)$
$\mathrm{a}_{\max }\left(\mathrm{m}^{2}\right)$

$78.78154 \pm 15.97199$

$1.450967 \pm 0.2311324$

$45.94133 \pm 0.3250943$

$22.56798 \pm 1.163239$

$18.76534 \pm 0.795097$

$531.2491 \pm 9.422656$

$424.2147 \pm 38.55961$

$5.09 \times 10^{-11} \pm 4.63 \times 10^{-12}$

$1.970812 \pm 0.1286774$

$0.2252835 \pm 0.02416722$

$62.67824 \pm 4.528295$

$1.6754 \pm 0.2828074$

$49.17333 \pm 0.3177693$

$34.41614 \pm 2.221714$

$23.24443 \pm 2.705938$

$482.597 \pm 34.21093$

$804.192 \pm 142.1423$

$9.65 \times 10^{-11} \pm 1.71 \times 10^{-11}$
$59.90972 \pm 11.77134$

$2 \quad 1.5889$

0.253

$1.016927 \pm 0.08406959$

$46.096 \pm 1.558179$

$2 \quad 2.5476$

0.1257

$\begin{array}{ll}2 & 0.79461\end{array}$

0.5102

$23.61929 \pm 0.2441612$

$17.66817 \pm 0.1403888$

$321.339 \pm 84.23837$

$417.5601 \pm 4.491358$

$5.01 \times 10^{-11} \pm 5.39 \times 10^{-13}$

$1.219587 \pm 0.316791$

$0.1338221 \pm 0.03408966$

$93.00723 \pm 15.47025$

$2.233667 \pm 0.4679179$

$48.12367 \pm 1.054797$

$27.33326 \pm 1.354864$

$21.49169 \pm 0.3569846$

$505.3536 \pm 41.93203$

$587.8965 \pm 24.55734$

$7.06 \times 10^{-11} \pm 2.95 \times 10^{-12}$
$2 \quad-1.4112$

$2 \quad 2.8148$

24.1717

20.30188

$2 \quad 0.30188$

$2 \quad 3.262$

$2 \quad 2.259$

$\begin{array}{ll}2 & -2.9037\end{array}$

$2 \quad-1.7644$

21.3849

$2 \quad 3.6344$

21.1363

$2-0.6063$

$2 \quad 2.2587$

$2 \quad 2.2587$
0.06807

0.2936

0.1064

0.05294

0.7912

0.7912

0.08251

0.1524

0.101

0.2197

0.3003

0.3737

0.606

0.1524

0.1524 


\begin{tabular}{|c|c|c|c|c|c|c|}
\hline & $\mathrm{g}_{\mathrm{wmax}}\left(\operatorname{mol} \cdot \mathrm{m}^{-2} \cdot \mathrm{s}^{-1}\right)$ & $2.617168 \pm 0.2959412$ & $2.233592 \pm 0.1107773$ & 2 & 2.3988 & 0.1386 \\
\hline & SPI & $0.3888253 \pm 0.07956482$ & $0.2940954 \pm 0.01535773$ & 2 & 3.709 & 0.06562 \\
\hline & $\operatorname{SLA}\left(\mathrm{cm}^{2} \cdot \mathrm{g}^{-1}\right)$ & $45.67546 \pm 6.03813$ & $75.14152 \pm 2.240854$ & 2 & -11.904 & 0.00698 \\
\hline & $\mathrm{N}\left(\mu \mathrm{g} \cdot \mathrm{mm}^{-2}\right)$ & $0.9133433 \pm 0.01369764$ & $1.5613 \pm 0.1503436$ & 2 & -6.6609 & 0.0218 \\
\hline & $\mathrm{C}\left(\mu \mathrm{g} \cdot \mathrm{mm}^{-2}\right)$ & $45.46733 \pm 1.276498$ & $43.249 \pm 0.7815005$ & 2 & 3.1866 & 0.08597 \\
\hline Xylopia & $\mathrm{L}(\mu \mathrm{m})$ & $21.91995 \pm 0.2855288$ & $19.07653 \pm 1.182216$ & 2 & 3.7743 & 0.06358 \\
\hline & $\mathrm{W}(\mu \mathrm{m})$ & $14.14179 \pm 0.4635731$ & $12.38699 \pm 0.5515385$ & 2 & 3.1704 & 0.08674 \\
\hline & $\mathrm{D}\left(\mathrm{mm}^{-2}\right)$ & $554.9866 \pm 37.74419$ & $252.6768 \pm 9.783346$ & 2 & 11.389 & 0.00762 \\
\hline & $\mathrm{S}\left(\mu \mathrm{m}^{2}\right)$ & $309.881 \pm 6.838657$ & $236.2895 \pm 16.24355$ & 2 & 8.6382 & 0.01314 \\
\hline & $\mathrm{a}_{\max }\left(\mathrm{m}^{2}\right)$ & $3.72 \times 10^{-11} \pm 8.21 \times 10^{-13}$ & $2.84 \times 10^{-11} \pm 1.95 \times 10^{-12}$ & 2 & 8.6386 & 0.01314 \\
\hline & $\mathrm{g}_{\mathrm{wmax}}\left(\operatorname{mol} \cdot \mathrm{m}^{-2} \cdot \mathrm{s}^{-1}\right)$ & $1.896808 \pm 0.1387527$ & $0.7509352 \pm 0.007626135$ & 2 & 14.665 & 0.00462 \\
\hline & SPI & $0.1720715 \pm 0.01283689$ & $0.05954519 \pm 0.002152261$ & 2 & 13.287 & 0.00562 \\
\hline & $\operatorname{SLA}\left(\mathrm{cm}^{2} \cdot \mathrm{g}^{-1}\right)$ & $82.65991 \pm 4.399838$ & $136.6343 \pm 8.490796$ & 2 & -10.303 & 0.00929 \\
\hline & $\mathrm{N}\left(\mu \mathrm{g} \cdot \mathrm{mm}^{-2}\right)$ & $2.2707 \pm 0.1745811$ & $1.879 \pm 0.06863214$ & 2 & 3.2676 & 0.08226 \\
\hline & $\mathrm{C}\left(\mu \mathrm{g} \cdot \mathrm{mm}^{-2}\right)$ & $52.67133 \pm 0.3265032$ & $50.65667 \pm 0.6819988$ & 2 & 5.0847 & 0.03657 \\
\hline
\end{tabular}

